http://economix.fr

\title{
Jumps in Equilibrium Prices and Asymmetric News in Foreign Exchange Markets
}

Document de Travail

Working Paper

2015-14
Imane El Ouadghiri Remzi Uctum

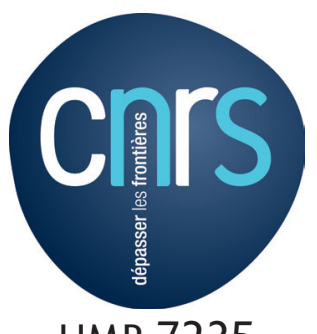

UMR 7235
Université de Paris Ouest Nanterre La Défense (bâtiment G) 200, Avenue de la République 92001 NANTERRE CEDEX université

Paris Ouest

Nanterre La Défense 


\title{
Jumps in Equilibrium Prices and Asymmetric News in Foreign Exchange Markets*
}

\author{
Imane El Ouadghiri $\quad$ Remzi Uctum ${ }^{\ddagger}$
}

May 28, 2015

\begin{abstract}
In this paper we examine the intraday effects of surprises from scheduled and unscheduled announcements on six major exchange rate returns (jumps) using an extension of the standard Tobit model with heteroskedastic and asymmetric errors. Since observed volatility at high frequency often contains microstructure noise, we use a recently proposed non parametric test to filter out noise and extract jumps from noise-free FX returns (Lee and Mykland (2012)). We found that the most influential scheduled macroeconomic news are globally related to job markets, output growth indicators and public debt. These surprises impact FX jumps rather in the form of good news, as a result of pessimistic forecasts from traders during the crisis period analyzed. We reconfirmed for most of the currencies the hypothesis that negative volatility shocks have a greater impact on volatility than positive shocks of the same magnitude, reflecting markets' concern about the cost of stabilization policies.
\end{abstract}

JEL Classification: G14, G12, E44, C22.

Keywords: Forex market, announcements, jump detection test, high frequency data, microstructure noise, asymmetric GARCH.

\footnotetext{
${ }^{*}$ We are especially grateful to Elena Dumitrescu for kindly providing assistance in programming and for helpful discussions. We also thank Valérie Mignon and Sébastien Laurent for helpful remarks and suggestions.

${ }^{\dagger}$ EconomiX-CNRS, University of Paris Ouest, 200 av. de la République, 92001 Nanterre Cedex. France, Tel: +33 (0)1 409759 63, E-mail: imane.elouadghiri@u-paris10.fr.

${ }^{\ddagger}$ Corresponding author; EconomiX-CNRS, University of Paris Ouest, 200 av. de la République, 92001 Nanterre Cedex. France, Tel : +33 (0)1 409778 48, E-mail: uctum@u-paris10.fr.
} 


\section{Introduction}

Understanding asset price volatility is a crucial goal for traders and portfolio managers involved in asset pricing, portfolio allocation and hedging strategies against portfolio risk. While standard volatility models such as GARCH or stochastic volatility models have been successful to fit the dynamic features of financial return series up to daily frequencies, they have proven inadequate at higher frequencies because of their inconsistency to represent the market microstructure patterns emerging at the intraday level. With the availability of tick-by-tick data, a wide strand of the literature on volatility modeling has pointed at the role of intraday periodic patterns and of macroeconomic news releases. Intraday volatility results from any regular intraday patterns such as openings and closings of financial markets (Andersen and Bollerslev (1997); Erdemlioglu et al. (2012)). As for announcements effects, Andersen et al. (2003), Laakkonen (2007), Lee and Mykland (2008), and Lahaye et al. (2011) among others, have shown that some of major expected macroeconomic news - such as the consumer price index, ISM (Institute of Supply Management) manufacturing index, consumer confidence index, retail sales, producer price index, non-farm payrolls and news related to the labor market to name a few - tend to be a real catalyst for short-term movements in financial markets, generating large changes in market volatility thereby causing abnormally large returns called 'Jumps' in price dynamics. Jumps are significant large responses of the market surprises to scheduled news on which the community of analysts regularly provides their expectations and to unscheduled news. They occur frequently in the Forex markets, responding not only to U.S. economic news but also to news from around the world because exchange rate is a worldwide sensitive variable.

Identifying jumps in a price process has been explored by a widespread literature. Since the seminal contributions of Barndorff-Nielsen and Shephard (2004), the econometric literature has made tremendous progress on how to detect jumps at high frequency in univariate price process. Lee and Mykland (2008) have provided a major advance in proposing a non parametric test, which Boudt et al. (2011) have improved by introducing a market intraweek seasonality in the instantaneous price volatility. Recently, Lee and Mykland (2012) have proposed a non parametric test controlling for microstructure noise.

The connection between jumps in the exchange rates and the scheduled macroeconomic news has been examined extensively in recent decades, with pioneering studies ${ }^{1}$ that have been implemented to investigate the efficient capital market hypothesis. Evans and Lyons (2005) find that arrival of scheduled announcements produce the largest exchange rate changes and that the impact of news remains significant for several days. BarndorffNielsen and Shephard (2006) apply their bipower variation procedure to estimate jumps on USD/DEM and USD/JPY exchange rates data by relating the jump days to those of macroeconomic announcements. Andersen and Vega (2007) find evidence of jumps in exchange rates, S\&P 500 futures and U.S. Treasury bond futures. The authors also show that these jumps are related to news events and that the jump component has a large magnitude and a lower persistence than the corresponding continuous component

\footnotetext{
${ }^{1}$ Fama (1965), Ball and Brown (1968), Fama and Schwert (1977)
} 
of the realized volatility. Lahaye et al. (2011) use the non parametric test of Lee and Mykland (2008) that they expand by integrating the market intraweek seasonality in the instantaneous price volatility as in Boudt et al. (2011). The authors detect the presence of jumps in a variety of financial asset prices (exchange rates, equities and bonds) and, using a Tobit-GARCH model, demonstrate that U.S. macro announcements significantly contribute to explaining jumps and cojumps in financial returns. With regard to foreign exchange rates, Lahaye et al. (2011) identify the non farm-payroll, federal funds target releases, GDP, consumer confidence and trade balance shocks as being the most influential macroeconomic news. In short, most papers concerned with the question of the impact of announcement releases on returns report that macroeconomic news exert a significant influence on exchange rate jumps and thereby play a role in the volatility of the Forex market.

Our paper aims to contribute to this literature by examining what types of news surprises influence the movements in six exchange rate returns (EUR, GBP, JPY, AUD, CAD, CHF in terms of USD) from June 2007 to June 2012 using high frequency data. It departs from the previous studies in several respects. Firstly, following Lahaye et al. (2011), we represent the jump process using a Tobit-GARCH class of models (Calzolari and Fiorentini, 1998). This methodology is particularly appropriate for modeling financial jump variables whose values are given by abnormal returns when they are statistically significant and by zero otherwise; such jump variables are therefore measured by censored data (Tobit specification). The GARCH specification for the errors is motivated by the fact that since Mandelbrot (1963), financial returns are known to exhibit volatility clustering patterns at daily or higher frequencies. However, financial asset prices are also characterized by the empirically observed fact that negative shocks have a stronger impact on volatility than positive shocks (this is the so-called leverage effect when stock market are considered). In order to account for this asymmetry, we go further than the previous studies and replace the GARCH process with the more general GJR-GARCH model introduced by Glosten et al. (1993). We qualify the latter as general since for a zero value of the leverage coefficient (no asymmetry) it reduces to a standard GARCH. We thus estimate our exchange rate jump model using a Tobit-GJR-GARCH framework, which to our best knowledge has never been applied to Forex market data. Secondly, we consider two categories of news impacting jumps : scheduled macroeconomic news provided by Bloomberg at specific dates of each month and which are partially expected by traders, and unscheduled news, which consist in unexpected negative real shocks, such as the bankruptcy of some major banks during the subprime crisis, the downgrading of banks' and countries' ratings, the Great East Japan Earthquake of March, 2011 and some other key events. ${ }^{2}$ Thirdly, we devote special attention to the question of removing microstructural noise from observed prices. ${ }^{3}$ Previous studies, whether they rely on the Lee and Mykland (2008) non parametric statistical procedure, the Barndorff-Nielsen and Shephard test (2004) or the

\footnotetext{
${ }^{2}$ See Appendix 4 for more details

${ }^{3}$ Microstructural noise represent frictions that can distort trading activity such as transaction costs, liquidity shortages, information asymmetry, bid-ask bounces, errors in the measurement of the observed price.
} 
Jiang-Oomen test (2008) to extract jumps around news events, often ignore the presence of microstructure noise in observed price data. Consequently, instead of identifying jumps in equilibrium (noise-free) prices, they discover them in the observed prices. Thus, very large changes featured by observed prices and due to some sizable market frictions (noise) may be wrongly interpreted as strategic responses from investors (jumps). To avoid this pitfall, we use a recent breakthrough non parametric jump detection test proposed by Lee and Mykland (2012), which allows for asymptotically removing microstructural noise from observed prices by an appropriate frequency re-sampling procedure. ${ }^{4}$ Our approach is innovating in that, to our knowledge, no previous empirical study using high frequency data has ever employed this methodology to appropriately detect jumps or simply model asset price volatility.

The use of the new Lee and Mykland (2012) non parametric test reveals that significant jumps represent about $0.41 \%$ of all denoised returns and that our scheduled macro news and unscheduled events explain about $34 \%$ and $14 \%$ of total jumps, respectively. Macroeconomic surprises impact FX jumps rather in the form of good news, reflecting pessimistic forecasts from traders during the crisis period analysed. Significant scheduled macro news concern globally job markets, output growth indicators and public debt. Significant unscheduled events shocks include the Madoff fraud and subprime crisis rescue plans.

The rest of the paper proceeds as follows. Section 2 describes the data used, while Section 3 surveys the main jump detection methods and explains in detail the one we will employ. Section 4 presents our Tobit-GJR-GARCH jump model while estimation results are discussed in Section 5. Section 6 concludes.

\footnotetext{
${ }^{4}$ Note that some studies have set the noise-eliminating sampling frequency using heuristic approaches. However the choice of the frequency remains arbitrary, leading potentially to a partial elimination of microstructural noise.
} 


\section{Data Description}

\subsection{Exchange Rates}

We consider one-minute intraday returns in six currencies against the US Dollar (USD): Australian Dollar (AUD), Canadian Dollar (CAD), Swiss Franc (CHF), Euro (EUR), British Pound (GBP) and Japanese Yen (JPY). All the exchange rate series are provided by Olsen \& Associates and Dukascopy. The full sample spans from June 1, 2007 to June 30, 2012. All times are GMT. The FX markets trade 24-hours a day. This implies that each trading day has 1440 one-minute intraday intervals. Due to the lack of observations, the weekends were removed from our data, from Friday midnight to Sunday midnight. After removing from our database weekends and days where there are too many missing values, we end-up with 1527 trading days over the period considered, and a total of 1,908,040 observations for the EUR/USD exchange rate and 1,909,380 for the others.
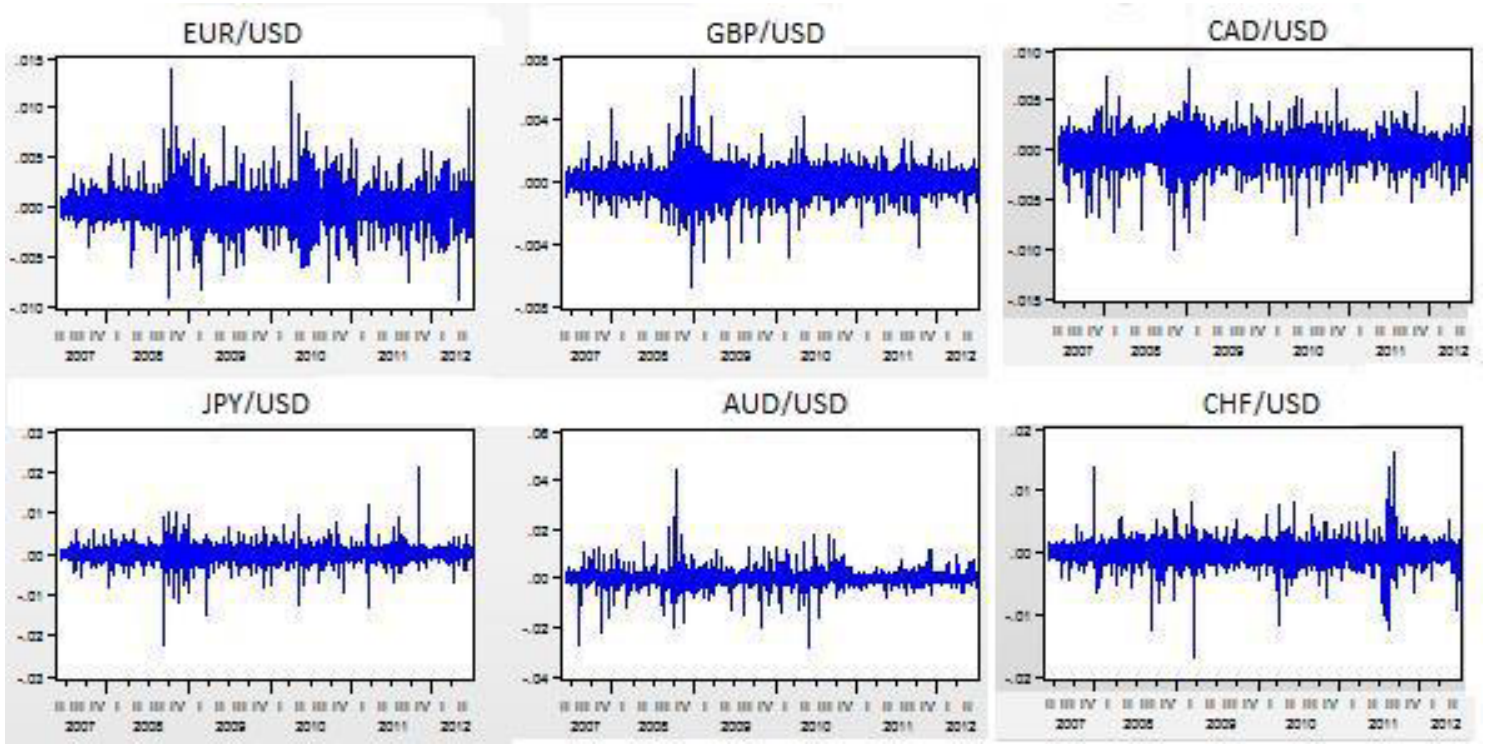

Figure 1: Forex returns

Figure 1 shows the dynamics of our six foreign exchange rate returns. All series exhibit an increase in volatility at the fourth quarter of 2008, which corresponds to the beginning of the financial crisis marked by the collapse of several banks and in particular Lehman Brothers' bankruptcy on September 15, 2008. The reaction of the six foreign exchange markets seems to be synchronized around this quarter and the first quarter of 2009 because the financial crisis hit all the markets, with a lesser extent the Swiss franc due to the faster reaction of the Swiss banking system. The EUR/USD returns exhibit also high volatility at the second quarter of 2010, due to the intensification of the Euro zone debt crisis, mostly centered in Greece. Beside the main clusters, many other negative and positive jumps are featured by the exchange rate returns. These jumps may reflect financial traders' behavioral responses to (i) surprises from their forecasts on scheduled announcements, (ii) unexpected unscheduled events and (iii) calendar (intraday or intraweek) periodicity. But they may also include a number of spurious jumps or microstructural noise, due to market 
frictions, that can spoil the data at the very high frequency. The aim of the following sections is to disentangle the true Forex returns and market microstructure noise by preprocessing the data, so that observed jumps such as the ones in Figure 1 only stem from large spreads of true returns.

\subsection{Announcements and economic news}

\subsubsection{Scheduled macroeconomic news}

We define a surprise as a large difference between a released value of a major scheduled macroeconomic news and the market expectation, which we proxy using financial experts' median expectation provided by the Bloomberg "World Economic Calendar" (WECO) survey. ${ }^{5}$ We follow Balduzzi et al. (2001) and standardize the forecast error in each news announcement so that the surprise values for various types of news are comparable. The surprise $S_{k}\left(t_{i}\right)$ related to the news announcement $k$ is then written as:

$$
S_{k}\left(t_{i}\right)=\frac{A_{k}\left(t_{i}\right)-F_{k}\left(t_{i}\right)}{\hat{\sigma_{k}}}
$$

where $t_{i}$ stands for the intraday time $i$ of day $t, A_{k}\left(t_{i}\right)$ represents the release of the announcement $k$ at time $t_{i}, F_{k}\left(t_{i}\right)$ the median of the survey forecast on the announcement $k$ scheduled at the horizon $t_{i}$ and $\hat{\sigma}_{k}$ the standard deviation of the forecast error $A_{k}\left(t_{i}\right)-F_{k}\left(t_{i}\right)$. The forecast errors are standardized so that the surprises from releases of different types and reporting conventions are comparable.

We cover an extensive list of announcements comprising the ones used in previous literature and also other announcements. Tables (a) to (e) in Appendix 3 present a summary of all announcements that are likely to trigger sudden price movements, or jumps. These announcements are from the USA, Japan, China, U.K. and the Euro zone, from January 2007 to December 2012 with monthly frequencies. We include announcements from major fields of the economies, called "Market Movers Indicators", and announcements specific to each country. We also include the macroeconomic announcements although they are well anticipated by the market such as Central Banks' target rates. We end up with 47 announcements for the U.S. economy, 12 for China, 6 for the Euro area and 23 for U.K. and Japan. For all these scheduled macro announcements, negative surprises have been separated from positive ones in order to study the asymmetry in producing increased volatility.

Figures (a) to (f) in Appendix 1 display the price dynamics around some scheduled publications. It can be seen that for some news, the market responds almost immediately to the releases by sharp and positive or negative jumps. This confirms that information

\footnotetext{
${ }^{5}$ Between 80 and 100 financial experts from major companies are asked by Bloomberg to provide their forecasts for each announcement. One week before the announcement is released, Bloomberg computes and publishes the median response as a proxy of the market expectation. Given the size of the panel of respondents and the leading positions of the forecasting agencies and financial institutions represented by the surveyed experts we can consider that the median response represents accurately the market expectation.
} 
is incorporated into the exchange rate very quickly since it lasts no more than a few minutes if not seconds, in line with the findings of Cheung and Chinn (2001). By contrast, Evans and Lyons (2005) show that in currency markets, the impact of U.S. and German announcements effects can persist up to several days. Appendix 1 also plots some anticipated responses to news announcements. In the minutes before a release, movements widen as some market makers pull their orders in anticipation of upcoming volatility.

\subsubsection{Unscheduled event news}

Jumps can result from unscheduled, therefore totally unexpected news releases. These are, for example, unforeseen official statements, central bank governors' ${ }^{6}$ or politicians ${ }^{6}$ decisions, declarations of bankruptcy from major banks or corporates, announcements from rating agencies or some natural disasters. We account for each of these unanticipated events through a dummy variable. Appendix 4 displays some of the key events that occurred between 2007 and 2012 that we include in our analysis.

To construct unscheduled news data, we first identify major events that happened from January 2007 to December 2012 in the five countries considered in this study. Then, we extract the releases with their exact occurring time from the Reuters and Bloomberg sources of the real-time financial news database Factiva. For each event, we create a dummy variable taking the value 1 at the day of the event and zero elsewhere. We examine fortyfive unanticipated events ranging from Lehman brothers bankcruptcy or Bernard Madoff fraud to the Great East Japan Earthquake. These news are fully unexpected because they correspond to isolated events or sometimes events that are unknown to the markets a priori. Note that most of them are not related directly to markets.

As an example of unscheduled news, Figure (a) in Appendix 2 illustrates for AUD/USD (left panel) and EUR/USD (right panel) that markets have reacted to President Obama's election on November 6, 2012 at 08:11 p.m. (November 7 at 03:11 a.m. GMT) by selling the safe-haven dollar against most of other currencies. The dollar fell on the view that the Fed will be encouraged to proceed on its quantitative easing path and that this policy will persist after Bernanke's end of term.

Figure (b) in Appendix 2 (left panel) displays the evolution of the JPY/USD exchange rate at 10:57 GMT on March 11, 2011, the day when "the Great East Japan earthquake" occurred. In the immediate aftermath of the earthquake (05:46 GMT), investors were prompted to sell the Japanese currency, which led the Yen to depreciate sharply. Thus, from the economic point of view, this natural disaster can be interpreted as an unexpected negative real shock in the Japanese economy and in particular on its currency. Both panels show that this jump in the currency has rapidly reversed and soared against the major currencies under the effect of the speculation that Japanese investors would repatriate assets to pay for rebuilding. 


\section{Detecting jumps}

As shown, market prices tend to exhibit frequent jumps in their dynamics. To prevent risk, investors need therefore to better understand and forecast this phenomenon. A jump is a sudden price movement where an abnormally large variation in the price process can be observed resulting from a buying and selling pressure. Jumps are therefore remarkable events as they can trigger important losses or gains for investors yielding significant portfolio reallocations. Theoretically, they can be represented by a continuous-time jump-diffusion process. Let the scalar logarithmic asset price $S(t)$ follow an Ito process augmented by a jump component. The dynamic of $S(t)$ is written as :

$$
d \log S(t)=\mu(t) d t+\sigma(t) d W(t)+C(t) d J(t),
$$

where $\mu(t)$ denotes the drift term, $\sigma(t)$ the instantaneous volatility process assumed to be càdlàg ${ }^{6} ; W(t)$ is a standard Brownian motion; $C(t) d J(t)$ a pure jump component assumed to follow a compound Poisson process since we are interested in large and infrequent price movements. $J(t)$ is the counting process, while $C(t)$ is the jump size. $J(t), C(t)$ and $W(t)$ are assumed to be mutually independent. The asset log-prices $p(t)$ are observed in discrete time $t$.

We denote the corresponding discrete-time intra-day geometric returns by:

$$
r\left(t_{i}\right) \equiv p\left(t+\frac{i}{M}\right)-p\left(t+\frac{(i-1)}{M}\right), \quad i=1, \ldots, M
$$

where $r\left(t_{i}\right)$ is the $i$ th return of day $t$ and $M$ refers to the number of equally spaced intraday returns observations over the trading day. When a jump occurs at time $t_{i}$, the return at this specific time $r\left(t_{i}\right)$ is expected to be much larger than in its regular continuous sample path. The objective of the jump test is to differentiate between jumps and instantaneous volatility that might produce incidentally large fluctuations in asset price returns.

\subsection{A review of the usual jump tests}

\subsubsection{The BNS Test}

Barndorff-Nielsen and Shephard (2004), or BNS, proposed an asymptotic non parametric test where they develop a jump robust measure of the daily integrated variance called realized bipower variation. The statistic is then computed as the relative difference between the realized variance and the bipower variation. The BNS statistic, called "relative jump measure", is calculated as follows :

$$
R J(t)=\frac{R V(t)-B V(t)}{R V(t)}
$$

where $R V(t)$ is the realized variance which converges uniformly in probability to the integrated volatility augmented by a term of accumulated instantaneous jumps (Andersen and

\footnotetext{
${ }^{6} \mathrm{~A}$ càdlàg (in French: "continue à droite, limite à gauche") is a function defined on the real numbers that is right-continuous with left limits everywhere.
} 
Vega, 2007):

$$
R V(t)=\sum_{i=1}^{M} r\left(t_{i}\right)^{2} \rightarrow \int_{0}^{T} \sigma^{2}(s) d s+\sum_{0<s \leq t} C^{2}(s),
$$

and the other component $B V(t)$ is the realized bipower variation, defined as:

$$
B V(t)=(2 / \pi)^{-1}\left(\frac{M}{M-1}\right) \sum_{i=2}^{M}\left|r\left(t_{i-1}\right)\right|\left|r\left(t_{i}\right)\right|
$$

An equivalent statistic, $-R V(t)$, called the "ratio statistic", is proposed and studied in Barndorff-Nielsen and Shephard (2006).

\subsubsection{The Jiang-Oomen Test}

Jiang and Oomen (2008), or JO, exploited the higher-order sample moments of returns to identify periods that contain jumps and constructed a test based on the hedging error of a swap variance replication strategy :

$$
S w V(t)-R V(t)=\frac{1}{3} \sum_{i=1}^{M} r\left(t_{i}\right)^{3}+\frac{1}{12} \sum_{i=1}^{M} r\left(t_{i}\right)^{4}+\ldots
$$

The swap variance " $S w V$ " is given by:

$$
S w V(t)=2 \sum_{i=1}^{M}\left(R\left(t_{i}\right)-r\left(t_{i}\right)\right)
$$

where $r\left(t_{i}\right)$ is the geometric return defined in the jump-diffusion process, and $R\left(t_{i}\right)$ is the arithmetic return $\frac{P\left(t_{i}\right)-P\left(t_{i-1}\right)}{P\left(t_{i-1}\right)}$. JO formulate several $z$-statistics that test the null hypothesis of no jumps in a sample period.

\subsubsection{The Lee and Mykland Test}

Lee and Mykland (2008), or LM, compared the magnitude of each change with a slidingwindow measure of local volatility and introduced a non parametric test which was assessed by simulation. As discussed by Fan and Fan (2011), the LM test outperforms the BNS and JO tests. LM proposed to standardize the absolute high frequency returns by a robust estimate of its instantaneous volatility, which is the average of realized bipower variation over the window $K=\sqrt{M \times 252},{ }^{7}$ thus providing a measure that explains the local variation only from the continuous part.

The statistic $\mathcal{L}\left(t_{i}\right)$, which tests at time $t_{i}$ whether there was a jump in the asset return from $t_{i-1}$ to $t_{i}$ is defined as:

$$
\mathcal{L}\left(t_{i}\right) \equiv \frac{\left|r\left(t_{i}\right)\right|}{\widehat{\sigma\left(t_{i-1}\right)}}
$$

\footnotetext{
${ }^{7}$ There is a trade-off in choosing the window size $K: K$ must be large enough to accurately estimate integrated volatility but small enough for the variable to be approximately constant over the window.
} 
where

$$
{\widehat{\sigma\left(t_{i-1}\right.}}^{2} \equiv \frac{1}{k-2} \sum_{j=i-k+2}^{i-1}\left|r\left(t_{j}\right)\right|\left|r\left(t_{j-1}\right)\right| .
$$

The idea behind this test is that if the observed value of the Lee \& Mykland statistic does not lie in the region of maximum returns, it is unlikely that the realized returns are generated by the diffusion model without jumps. Under the null of no jumps between $t_{i-1}$ to $t_{i}$, the statistic $\mathcal{L}\left(t_{i}\right)$ converges in distribution to the absolute value of a standard normal random variable. ${ }^{8}$ Besides, as shown by Galambos (1987), the maximum of a standard normal random variable follows a Gumbel distribution. For a given test size, it is then possible to check whether or not a standardized return observation is identifiable with a jump. This test is considered as being among the most important research works on jump detections and applications. However, it presents an important weakness. LM show that their jump test has good power at the 15-minute frequency, and that above this frequency a large number of detected jumps are spurious because of the presence of microstructure noise in price data. Microstructural noise represents frictions that can affect the trading process at very high frequencies, such as transaction costs or liquidity shortages.

To deal with the microstructure noise problem, Lee and Mykland (2012) proposed a new parametric test which allows to asymptotically remove noise from the observed log price in order to determine jumps directly in the equilibrium or noise-free log price. The $\log$ price observed at time $t_{i}$ denoted $\tilde{p}\left(t_{i}\right)$ is determined by the true log price $p\left(t_{i}\right)$ and by market microstructure noise $u\left(t_{i}\right)$ :

$$
\tilde{p}\left(t_{i}\right)=p\left(t_{i}\right)+u\left(t_{i}\right)
$$

where the noise distribution is assumed to be stationary and given by $u\left(t_{i}\right) \sim_{\mathcal{D}}\left(0, q^{2}\right)$ Thus, the noise follows a general process with mean zero and standard deviation $q$, which the authors call the "market quality parameter" and represents the degree of market imperfection. This is because when $q=0, u\left(t_{i}\right)=E\left(u\left(t_{i}\right)\right)=0$ and we get a frictionless market where the equilibrium asset price is directly observed. The principle of LM's procedure consists in pre-averaging the observed high frequency price data over appropriately chosen non-overlapping blocks so that asymptotically noise is removed from the observed prices. It focuses on the property that microstructure noise is time-dependent as evidenced by empirical studies (see, among others, Lunde and Hansen (2004)). Since the order of noise dependence is not observable, the authors suggest to infer it from the lag order of the autocorrelation function of the observed returns. Let $k-1$ denote the number of dependence lags resulting from the estimation of this function, the first step is to collect all the $k^{\text {th }}$ independent observations $\tilde{p}\left(t_{i}\right), i=0, k, 2 k, \ldots$ Let now $M$ represent the optimal block size (that is, the number of observations $\tilde{p}\left(t_{i}\right)$ to be pre-averaged) allowing to remove noise in observed log prices. Averaging log prices over non overlapping consecutive sets of $M$ terms yields to denoised log prices:

\footnotetext{
${ }^{8}$ See Theorem 1 in Lee and Mykland (2008).
} 


$$
\hat{p}\left(t_{j}\right)=\frac{1}{M}\left[\tilde{p}\left(t_{j}\right)+\tilde{p}\left(t_{j+k}\right)+\tilde{p}\left(t_{j+2 k}\right)+\ldots+\tilde{p}\left(t_{j+k(M-1)}\right)\right]
$$

where $j \in \mathcal{J}=\{0, k M, 2 k M, \ldots\}$. This re-sampling process ensures that any abnormal variation between $\hat{p}\left(t_{j+k M}\right)$ and $\hat{p}\left(t_{j}\right)$ does not result from noise, but signals the presence of a jump in the equilibrium price between the same observation times.

For equation (12) to be of practical use, it remains to determine the optimal block size $M$. Lee and Mykland (2012) suggest the rule of thumb according to which $M=C(q)[n / k]^{\frac{1}{2}}$ when $n \longrightarrow \infty$, where $n$ is the number of independent observations $\tilde{p}\left(t_{i}\right)$ and $C(q)$ is a constant parameter depending positively on the standard deviation $q$ since, as stated by the authors, the greater the noise standard deviation, the larger must be the block size for pre-averaging. The authors provide a list of values for this parameter that they obtain by simulation for different values of $q .^{9}$ They also propose an estimator for the latter that is robust to the presence of jumps, ${ }^{10}$ defined as :

$$
\hat{q}=\frac{1}{\sqrt{2}}\left[\frac{1}{n-k} \sum_{s=1}^{n-k}\left(\tilde{p}\left(t_{s+k}\right)-\tilde{p}\left(t_{s}\right)\right)^{2}\right]^{1 / 2}
$$

It is now possible to define the statistic $\Psi\left(t_{j}\right) \equiv \hat{p}\left(t_{j+k M}\right)-\hat{p}\left(t_{j}\right), j \in \mathcal{J}$, to test for the presence of jumps in the equilibrium prices between $t_{j+k M}$ and $t_{j}$. Under the null of no jumps, $\Theta\left(t_{j}\right)=\Psi\left(t_{j}\right) / \sqrt{V\left(\Psi\left(t_{j}\right)\right)}$ is standard normal and $\xi_{n}=\left(\max _{t_{j}, j \in \mathcal{J}}\left|\Theta\left(t_{j}\right)\right|-A_{n}\right) / B_{n}$ follows a standard Gumbel distribution as $n \longrightarrow \infty$, where $A_{n}=\sqrt{C_{n}}-\frac{\log (\pi)+\log \left(\log \left(\frac{n}{k M}\right)\right)}{2 \sqrt{C_{n}}}$ $B_{n}=1 / \sqrt{C_{n}}$ and $C_{n}=2 \log (n / k M)$. Hence, the cumulative distribution function of $\xi_{n}$ is $P\left(\xi_{n} \leq\left(G_{n}-A_{n}\right) / B_{n}\right)=\exp \left[-\exp \left(-\left(G_{n}-A_{n}\right) / B_{n}\right)\right]$, where $G_{n}$ is a positive real number. The asymptotic critical value $G_{n, \alpha}$ for rejecting the null at the $100 \alpha \%$ level of significance is such that $P\left(\xi_{n} \leq\left(G_{n, \alpha}-A_{n}\right) / B_{n}\right)=1-\alpha$, implying $G_{n, \alpha}=-\log (-\log (1-\alpha)) B_{n}+A_{n}$. It follows that at the $1 \%, 5 \%$ and $10 \%$ levels, we have $G_{n, 0.01}=4.6, G_{n, 0.05}=2.97$ and $G_{n, 0.10}=2.25$, respectively.

\footnotetext{
${ }^{9}$ See Lee and Mykland (2012) Table 5.

${ }^{10}$ See Lee and Mykland (2012), appendices $A 4$ and $A 5$.
} 


\subsection{Separating jumps from microstructural noise}

We now apply the Lee and Mykland (2012) test procedure described in subsection 3.1.3 to our FX data. Table 1 displays an overview of some results from the implementation of the denoising method and from the subsequent matching between macroeconomic news surprises and jumps, defined as significant changes in the true or denoised foreign exchange returns.

\begin{tabular}{|c|c|c|c|c|c|c|}
\hline DESC STAT JUMPS & EUR/USD & GBP/USD & JPY/USD & CHF/USD & AUD/USD & CAD/USD \\
\hline \#obs & 1908040 & 1909320 & 1909380 & 1909380 & 1909380 & 1909380 \\
\hline \#denoised obs & 18705 & 15152 & 15152 & 18720 & 18718 & 18720 \\
\hline denoising frequency & $102 \mathrm{~min}$ & $126 \min$ & $126 \min$ & $102 \min$ & $102 \mathrm{~min}$ & $102 \min$ \\
\hline$q$ & 0.0199 & 0.0135 & 0.0266 & 0.0222 & 0.0306 & 0.0222 \\
\hline$C$ & $1 / 19$ & $1 / 19$ & $1 / 19$ & $1 / 19$ & $1 / 19$ & $1 / 19$ \\
\hline$M$ & 51 & 42 & 42 & 51 & 51 & 51 \\
\hline \#trading days & 1325 & 1327 & 1327 & 1327 & 1327 & 1327 \\
\hline \#jumps & 60 & 65 & 72 & 66 & 99 & 77 \\
\hline $\mathrm{P}$ (\#jumps) & 0.32 & 0.43 & 0.47 & 0.35 & 0.53 & 0.41 \\
\hline \#jump days & 56 & 52 & 52 & 52 & 70 & 63 \\
\hline $\mathrm{P}$ (\#jump days $)$ & 4.22 & 3.92 & 3.92 & 3.92 & 5.27 & 4.75 \\
\hline $\mathrm{E}$ (\#jumps|\#jumpday) & 1.07 & 1.25 & 1.38 & 1.27 & 1.41 & 1.22 \\
\hline \multicolumn{7}{|l|}{ Asymmetry in Jumps } \\
\hline \#jumps $>0$ & 32 & 31 & 38 & 32 & 45 & 38 \\
\hline $\mathrm{P}(\#$ jumps $>0)$ & 53.33 & 47.69 & 52.77 & 48.4 & 45.45 & 49.35 \\
\hline $\mathrm{SD}$ & 6.44 & 6.19 & 5.88 & 6.15 & 5.004 & 5.69 \\
\hline$\#$ jumps $<0$ & 28 & 34 & 34 & 34 & 54 & 39 \\
\hline $\mathrm{P}(\#$ jumps $<0)$ & 46.67 & 52.30 & 47.22 & 51.51 & 54.54 & 50.65 \\
\hline SD & 6.44 & 6.19 & 5.88 & 5.10 & 4.99 & 5.41 \\
\hline \multicolumn{7}{|l|}{ MATCHING NEWS } \\
\hline \#surprises & 7686 & 7686 & 7686 & 7686 & 7686 & 7686 \\
\hline \#newsdays & 1527 & 1527 & 1527 & 1527 & 1527 & 1527 \\
\hline \#news & 113 & 113 & 113 & 113 & 113 & 113 \\
\hline \#news | \#jumps & 29 & 29 & 28 & 35 & 38 & 33 \\
\hline \#jumps | \#news & 20 & 22 & 27 & 25 & 26 & 27 \\
\hline $\mathrm{P}$ (\#news | \#jumps) (\%) & 25.66 & 24.78 & 25.66 & 33.63 & 29.20 & 30.97 \\
\hline $\mathrm{P}$ (\#jumps | \#news) (\%) & 33.33 & 37.50 & 33.85 & 26.26 & 35.06 & 37.88 \\
\hline
\end{tabular}

(\#denoised obs), the quality parameter $(q)$ the $q$-dependent optimal value $(\mathrm{C})$, the number of sample days (\#trading days), the total number of days with jumps (\#jump days), days with at least one jump, the probability (in \%) of a jump day ( $\mathrm{P}$ (jump day $)=100$ (\#jump days $\mid$ \#trading days)), the number of jumps per jump day (E(\#jumps $\mid$ jump day)=\# jumps|\#jump days), the total number jumps (\#jumps), their proportion (in \%) over the sample ( $\mathrm{P}($ jump $)=100$ (\#jumps $\mid$ \#obs)). The next panel reports proportions of positive jumps ( $\mathrm{P}($ jump $>0)$ and the paniations (SD). Finally, the last eviation ( of days match with at least one news (\#jump | news). The matching process in based on a time-span window of 102 or 126 minutes
depending on the currencies.

Table 1: Preliminary results: denoising and matching

One of the most noteworthy results displayed in the first panel of Table 1 are the denoising frequencies. For the EUR, AUD, CAD and CHF currencies, our initial oneminute frequency data were transformed into 1 hour and 42 minute frequency denoised data and for the GBP and JPY currencies, the initial one-minute data were transformed into 2 hours and 06 minutes frequency denoised data. Using these preprocessed data, we found that significant jumps occur at the frequencies of $0.32 \%$ for the Euro, $0.43 \%$ for the Pound, $0.47 \%$ for the Yen, $0.53 \%$ for the Australian dollar, $0.41 \%$ for the Canadian dollar and $0.35 \%$ for the Swiss franc. ${ }^{11}$ Our results are in line with Lahaye et al. (2011), who found that $0.36 \%$ of observed returns can be qualified as jumps. A slight asymmetry is observed for all FX rates (middle panel of Table 1): a negative asymmetry for the EUR and JPY and a positive one for the others.

\footnotetext{
${ }^{11}$ See more details in the Appendix 5.
} 

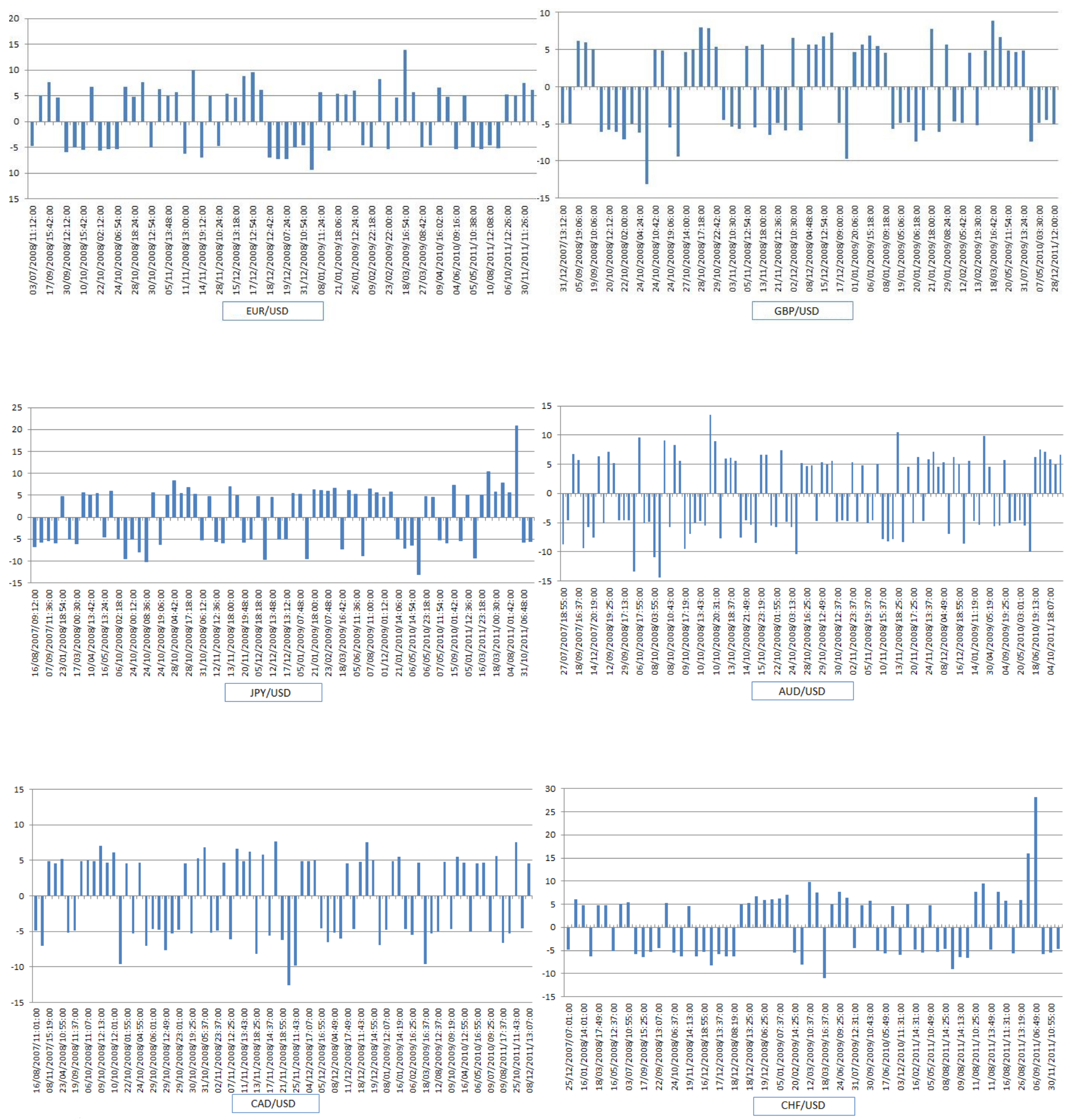

Figure 2: Jumps in major forex returns

Figure 2 presents these jumps for the six currencies considered. It appears that the magnitude of the jumps (the jump size) in absolute value typically varies around a $500 \%$ rate of change in all spot rates, with sporadic peaks reaching $1000 \%$ to $1500 \%$ in the 
case of EUR, GBP, AUD, CAD and CHF and more than $2000 \%$ in the case of JPY and CHF currencies. As expected, jumps are especially concentrated on the financial crisis period, reflecting the uncertainty that characterized the economies from the end of 2008 throughout 2009. The biggest jump in the EUR is positive and located on March 18, 2009, presumably in response to two news about US inflation that were announced before this jump or to traders' expectations on the US Federal Funds Target Rate. For the GBP, the biggest jump is negative and occurred on October 24, 2008, it coincides with a negative surprise on the UK GDP growth expectations. For the CHF currency, a very large positive jump can be noted on September 06, 2011. An obvious event that has at least partially given rise to this jump is the announcement, issued on the same day by the Swiss National Bank, that in order to depreciate the overvalued CHF currency the Bank intended to buy foreign currency in unlimited quantities, thereby leading the currency to loose $9 \%$ against the US dollar (according to the Guardian and BBC news). This event has been included in the unscheduled news database. We also tested for the impact of the announcement on the UK Trade Balance in Goods which has increased more than the consensus market has anticipated.

The last panel of Table 1 includes statistics resulting from a matching window between jumps and macroeconomic news. According to this window a matching occurs between a jump and a news if the latter precedes the former by up to 30 minutes or follows it by up to 5 minutes. The time discrepancy between the two events represents investors' response delay to the news release in the first case and their anticipation to upcoming volatility in the last case. ${ }^{12}$ Results show that, on average, $33.98 \%$ of jumps match our macroeconomic news. Appendix 5 provides further information on which news coincide with how many jumps.

\footnotetext{
${ }^{12}$ Note that matching news and jumps allows for collecting relevant news before estimation but is not informative about the significance of news nor the sign of their effects.
} 
Table 2 reports more details about the matching process between timestamped jumps and macroeconomic news.

\begin{tabular}{|c|c|c|c|c|c|c|}
\hline & 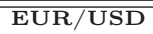 & "GBP/USD & JPY/USD & CHF/USD & AUD/USD & CAD/USD \\
\hline \multicolumn{7}{|c|}{ \#Jumps|Time slot } \\
\hline $00 \mathrm{H}-08 \mathrm{H}$ & 2 & 4 & 1 & 3 & 4 & 0 \\
\hline $08 \mathrm{H}-10 \mathrm{H}$ & 1 & 3 & 1 & 2 & 1 & 1 \\
\hline $10 \mathrm{H}-12 \mathrm{H}$ & 4 & 0 & 4 & 4 & 0 & 2 \\
\hline $12 \mathrm{H}-14 \mathrm{H}$ & 6 & 7 & 10 & 9 & 7 & 15 \\
\hline $14 \mathrm{H}-16 \mathrm{H}$ & 2 & 3 & 4 & 4 & 1 & 3 \\
\hline $16 \mathrm{H}-18 \mathrm{H}$ & 2 & 3 & 3 & 2 & 4 & 2 \\
\hline $18 \mathrm{H}-22 \mathrm{H}$ & 3 & 1 & 3 & 1 & 5 & 3 \\
\hline $22 \mathrm{H}-00 \mathrm{H}$ & 3 & 1 & 1 & 0 & 4 & 1 \\
\hline \multicolumn{7}{|c|}{ \#Jumps |Category of news } \\
\hline Monetary Policy & 17 & 6 & 4 & 15 & 5 & 6 \\
\hline Production Market & 9 & 14 & 13 & 14 & 9 & 12 \\
\hline Job Market & 11 & 5 & 25 & 16 & 2 & 20 \\
\hline Foreign Trade & 2 & 3 & 1 & 3 & 6 & 5 \\
\hline Retail market & 1 & 0 & 6 & 5 & 5 & 3 \\
\hline Inflation & 0 & 0 & 3 & 0 & 7 & 3 \\
\hline Housing Market & 2 & 7 & 4 & 3 & 8 & 5 \\
\hline \multicolumn{7}{|c|}{ \#Jumps $\mid$ Origin of news } \\
\hline EU & 3 & 4 & 0 & 2 & 0 & 0 \\
\hline UK & 8 & 4 & 2 & 8 & 6 & 2 \\
\hline $\mathrm{CN}$ & 0 & 1 & 0 & 6 & 0 & 0 \\
\hline JP & 8 & 2 & 1 & 0 & 8 & 1 \\
\hline US & 23 & 24 & 53 & 40 & 28 & 51 \\
\hline \multicolumn{7}{|c|}{ \#Jumps|Sign of news } \\
\hline \#NS-NJ & 8 & 9 & 4 & 8 & 7 & 4 \\
\hline \#PS-NJ & 7 & 6 & 7 & 1 & 7 & 3 \\
\hline \#NS-PJ & 11 & 9 & 7 & 11 & 8 & 11 \\
\hline \#PS-PJ & 6 & 8 & 13 & 7 & 10 & 6 \\
\hline
\end{tabular}

Table 2: Preliminarily results: jumps and news properties

It can be seen that the majority of jumps are detected between noon and two p.m. The Table also shows that over our sample, the JPY, CAD and CHF currencies react more to job market news, the EUR responds more to monetary policy news, the Pound and the Australian dollar are more sensitive to production news. All markets are responsive primarily to the U.S. news, followed by U.K. and Japanese news. Finally, the matching results suggest that positive surprises (PS) cause positive jumps (PJ) for the JPY and the AUD , and negative surprises (NS) cause positive jumps for the other currencies.

\section{Modeling Jumps: methodology and results}

Defining and computing jumps as statistically significant abnormal returns imply that series involve discontinuities as evidenced by Figure 2. In the following subsections we discuss and estimate the relationship between these jumps and macroeconomic announcements using an appropriate censored data model.

\subsection{Modeling Jumps using a Tobit model with asymmetric and het- eroskedastic errors}

To model jumps in exchange rate returns, we follow Lahaye et al. (2011) approach consisting in using a Tobit-GARCH model which is appropriate to examine in what extent discontinuous jumps are explained by macroeconomic announcement releases and calendar effects (interweekly and intradaily periodic effects), provided that the errors are conditionally heteroskedastic. We go further by taking into account an additional empirical feature commonly evidenced in financial markets, the leverage effect, which says that negative 
returns increase future volatility by a larger amount than positive returns of the same magnitude. To account for this asymmetry, we rely on a Tobit-GJR-GARCH model where the asymmetric conditional error variance specification is due to Glosten et al. (1993). ${ }^{13}$ Calzolari and Fiorentini (1998) have shown how to construct the log-likelihood of a TobitGARCH model. We apply their approach to the case of a Tobit-GJR-GARCH model.

We specify the standard Tobit model as follows:

$$
y\left(t_{i}\right)= \begin{cases}y^{*}\left(t_{i}\right) & \text { if } y^{*}\left(t_{i}\right)>0 \\ 0 & \text { if } y^{*}\left(t_{i}\right) \leq 0\end{cases}
$$

where $y^{*}\left(t_{i}\right)=x^{\prime}\left(t_{i}\right) \theta+u\left(t_{i}\right), u\left(t_{i}\right) \sim$ iid $\mathrm{N}(0, \sigma), y^{*}\left(t_{i}\right)$ is an unobservable (latent) random variable, $y\left(t_{i}\right)$ is the observed censored dependent variable, $x\left(t_{i}\right)$ is the vector of exogenous variables and $\theta$ is a vector of coefficients. When the dependent variable is the series of jumps, we posit $y\left(t_{i}\right)=\left|J\left(t_{i}\right)\right|$. This amounts to simplify the model as (see Lahaye et al. (2011)):

$$
\begin{gathered}
\left|J\left(t_{i}\right)\right|= \begin{cases}x^{\prime}\left(t_{i}\right) \theta+u\left(t_{i}\right) & \text { if } x^{\prime}\left(t_{i}\right) \theta+u\left(t_{i}\right)>0 \\
0 & \text { if } x^{\prime}\left(t_{i}\right) \theta+u\left(t_{i}\right) \leq 0\end{cases} \\
x^{\prime}\left(t_{i}\right) \theta=\mu+\lambda\left(t_{i}\right)+\delta\left(t_{i}\right)+\gamma\left(t_{i}\right)+\mathcal{F}\left(t_{i}\right)
\end{gathered}
$$

where $\left|J\left(t_{i}\right)\right|$ is the absolute value of significant jumps in foreign exchange returns at time $t_{i}, \lambda\left(t_{i}\right)$ and $\delta\left(t_{i}\right)$ stand for the impacts of surprises from scheduled and unscheduled announcements on significant jumps in foreign exchange returns at period $t_{i}$, while $\gamma\left(t_{i}\right)$ and $\mathcal{F}\left(t_{i}\right)$ represent the intraweek and intraday periodicities, respectively. We specify the effect of surprises from scheduled announcements as:

$$
\lambda\left(t_{i}\right)=\sum_{j=1}^{N^{+}} \lambda_{j}^{+} S_{j}^{+}\left(t_{i}\right)+\sum_{k=1}^{N^{-}} \lambda_{k}^{-}\left|S_{k}^{-}\left(t_{i}\right)\right|
$$

where $S_{j}^{+}\left(t_{i}\right)$ and $S_{k}^{-}\left(t_{i}\right)$ represent positive and negative standardized surprises associated with macroeconomic news announcements, while $N^{+}$and $N^{-}$are the number of positive and negative surprises, respectively. The coefficients $\lambda_{j}^{+}$and $\lambda_{k}^{-}$stand for the effect of the positive surprise $j$ and negative surprise $k$ on the forex jump magnitude. The effect of unscheduled news can be written as:

$$
\delta\left(t_{i}\right)=\sum_{f=1}^{Q} \delta_{f} F_{f}\left(t_{i}\right)
$$

where $F_{f}\left(t_{i}\right)$ is a dummy variable representing an unexpected event and $Q$ the number of such events. The coefficient $\delta_{f}$ identifies the once-for-all impact of the unexpected event on the jump magnitude. Calendar effects are taken into account through an intraweek

\footnotetext{
${ }^{13}$ Engle and $\mathrm{Ng}$ (1993) test different models capturing the asymmetry of the volatility response to news (EGARCH, Asymmetric-GARCH, VGARCH, Nonlinear-Asymmetric-GARCH and GJR-GARCH). In the light of various diagnostic tests, they find that all models show a greater impact of negative return shocks on volatility and that the GJR-GARCH model is the one which performs best.
} 
periodicity:

$$
\gamma\left(t_{i}\right)=\sum_{d=1}^{4} \gamma_{d} D_{d}\left(t_{i}\right)
$$

where $D_{d}\left(t_{i}\right)$ is a "day of the week" dummy which takes the value 1 when $t_{i}$ belongs to a business-day $\mathrm{d}\left(d=\right.$ Monday,..., Friday) and 0 otherwise $^{14}$, and through an intraday periodicity captured by the Flexible Fourier Form (FFF)(Andersen and Bollerslev, 1997)

$$
\mathcal{F}\left(t_{i}\right)=\vartheta_{0,1} \frac{n}{k 1}+\vartheta_{0,2} \frac{n^{2}}{k 2}+\sum_{p=1}^{P}\left[\vartheta_{c, p} \cos \left(\frac{2 \pi p n}{N}\right)+\vartheta_{s, p} \sin \left(\frac{2 \pi p n}{N}\right)\right]
$$

where $N$ is the number of intraday observations, $\vartheta_{0,1}, \vartheta_{0,2}, \vartheta_{c, p}$ and $\vartheta_{s, p}$ are coefficients to be estimated, $k_{1}=(N+1) / 2$ and $k_{2}=(N+1)(N+2) / 6$ are normalization constants and $P$ determines the number of phases in the daily cycle. After preliminary tests, we selected a daily cycle of four phases $(P=4)$.

Denoting $\phi$ and $\Phi$ the pdf and the cumulative density function of a standard normal, respectively, the non-linear Probit part of the likelihood (the one concerned by censored observations) is :

$$
\begin{aligned}
P\left[\left|J\left(t_{i}\right)\right|=0\right]=P\left[x^{\prime}\left(t_{i}\right) \theta+u\left(t_{i}\right) \leq 0\right]=P\left[u\left(t_{i}\right) \leq-x^{\prime}\left(t_{i}\right) \theta\right] & =P\left[\frac{u\left(t_{i}\right)}{\sigma} \leq \frac{-x^{\prime}\left(t_{i}\right) \theta}{\sigma}\right]= \\
\Phi\left(\frac{-x^{\prime}\left(t_{i}\right) \theta}{\sigma}\right) & =1-\Phi\left(\frac{x^{\prime}\left(t_{i}\right) \theta}{\sigma}\right)
\end{aligned}
$$

whereas the linear part concerned by the non-zero observations is:

$$
\begin{aligned}
P\left[\left|J\left(t_{i}\right)\right|=x^{\prime}\left(t_{i}\right) \theta+u\left(t_{i}\right)\right]=P\left[u\left(t_{i}\right)=\left|J\left(t_{i}\right)\right|-x^{\prime}\left(t_{i}\right) \theta\right] & =P\left[\frac{u\left(t_{i}\right)}{\sigma}=\frac{\left|J\left(t_{i}\right)\right|-x^{\prime}\left(t_{i}\right) \theta}{\sigma}\right]= \\
& \frac{1}{\sigma} \phi\left(\frac{\left|J\left(t_{i}\right)\right|-x^{\prime}\left(t_{i}\right) \theta}{\sigma}\right)
\end{aligned}
$$

The log-likelihood function is given by :

$L\left(\left|J\left(t_{i}\right)\right|, \theta, \sigma\right)=\sum_{0} \log \left[1-\Phi\left(\frac{x^{\prime}\left(t_{i}\right) \theta}{\sigma}\right)\right]-T_{1} \log (\sigma)-\frac{1}{2} T_{1} \log (2 \pi)-\frac{1}{2} \sum_{1}\left(\frac{\left|J\left(t_{i}\right)\right|-x^{\prime}\left(t_{i}\right) \theta}{\sigma}\right)^{2}$

where:

$\sum_{0}$ is the summation referring to the censored observations,

$\sum_{1}$ is the summation referring to the observed observations,

$T_{1}$ is the number of non zero observations.

\footnotetext{
${ }^{14}$ Andersen and Bollerslev (1998) show on the case of the DEM-USD exchange rate that forex volatility is sensitive to the day-of-the-week effects.
} 
We have supposed so far that the $u\left(t_{i}\right)$ 's are independently and identically distributed normal errors. To specify a Tobit-GJR-GARCH model we relax the assumption of iid normal errors in (14) and suppose that $u\left(t_{i}\right) \sim \mathrm{N}\left(0, \sigma\left(t_{i}\right)\right)$ where $\sigma\left(t_{i}\right)^{2}$ follows a GJR$\operatorname{GARCH}(p, m, q)$ process:

$$
\begin{gathered}
\sigma\left(t_{i}\right)^{2}=\omega+\sum_{j=1}^{p} \alpha_{j} u\left(t_{i-j}\right)^{2}+\sum_{k=1}^{m} \gamma_{k} \mathbb{I}\left(t_{i-k}\right) u\left(t_{i-k}\right)^{2}+\sum_{l=1}^{q} \beta_{l} \sigma\left(t_{i-l}\right)^{2} \\
\mathbb{I}\left(t_{i-k}\right)= \begin{cases}1 & \text { if } u\left(t_{i-k}\right)<0 \\
0 & \text { if } u\left(t_{i-k}\right) \geq 0\end{cases}
\end{gathered}
$$

where $\omega>0, \lambda_{j} \geq 0, \lambda_{k}>0, \beta_{l} \geq 0$ and $\sum_{j=1}^{p} \alpha_{j}+\frac{1}{2} \sum_{k=1}^{m} \gamma_{k}+\sum_{l=1}^{q} \beta_{l}<1 . \gamma_{k}$ is the leverage coefficient whose positivity ensures that negative shocks impact volatility by the coefficient $\alpha_{j}+\gamma_{k}$, while the effect of positive shocks is $\alpha_{j}$. When the dependent variable is observed, then for any lag $s=\{j, k\}$, the squared error in (23) can be written as :

$$
u\left(t_{i-s}\right)^{2}=\left[\left|J\left(t_{i-s}\right)\right|-x^{\prime}\left(t_{i-s}\right) \theta\right]^{2}
$$

When it is censored, i.e. $\left|J\left(t_{i-s}\right)\right|=0$, then $u\left(t_{i-s}\right)^{2}$ is proxied by its conditional expectation when $y^{*}\left(t_{i-s}\right) \leq 0$, that is $\tilde{u}\left(t_{i-s}\right)=E_{t_{i-s}}\left[u\left(t_{i-s}\right)^{2} / u\left(t_{i-s}\right) \leq-x^{\prime}\left(t_{i-s}\right) \theta\right]$. Calzolari and Fiorentini (1998) show that this approximation is given by:

$$
\tilde{u}\left(t_{i-s}\right)^{2}=\sigma\left(t_{i-s}\right)^{2}+x^{\prime}\left(t_{i-s}\right) \theta \frac{\sigma\left(t_{i-s}\right) \phi\left(t_{i-s}\right)}{1-\Phi\left(t_{i-s}\right)}
$$

where $\phi\left(t_{i}\right)=\phi\left(\frac{x^{\prime}\left(t_{i}\right) \theta}{\sigma\left(t_{i}\right)}\right)$ and $\Phi\left(t_{i}\right)=\Phi\left(\frac{x^{\prime}\left(t_{i}\right) \theta}{\sigma\left(t_{i}\right)}\right)$.

It remains to discuss the sign of $u\left(t_{i-k}\right)$ in (23) to assess for asymmetry. When the dependent variable is non-zero, the sign is that of $\left|J\left(t_{i-k}\right)\right|-x^{\prime}\left(t_{i-k}\right) \theta$. When it is not, it is natural from the preceding approximation to deduce the sign of $u\left(t_{i-k}\right)$ from that of its approximation $\tilde{u}\left(t_{i-k}\right)=E_{t_{i-k}}\left[u\left(t_{i-k}\right) / u\left(t_{i-k}\right) \leq-x^{\prime}\left(t_{i-k}\right) \theta\right]$. By simple integration, we can show that (see also Maddala (1983)):

$$
\tilde{u}\left(t_{i-k}\right)=-\frac{\sigma\left(t_{i-k}\right) \phi\left(t_{i-k}\right)}{1-\Phi\left(t_{i-k}\right)}
$$

The log-likelihood function becomes:

$$
\begin{gathered}
L\left(\left|J\left(t_{i}\right)\right|, \Theta\right)=L\left(\left|J\left(t_{i}\right)\right|, \theta, \omega, \alpha_{j}, \gamma_{k}, \beta_{l}, j=1, \ldots p, k=1, \ldots, m, l=1, \ldots, q\right)= \\
\sum_{0} \log \left[1-\Phi\left(\frac{x^{\prime}\left(t_{i}\right) \theta}{\sigma\left(t_{i}\right)}\right)\right]-\sum_{1} \log \left(\sigma\left(t_{i}\right)\right)-\frac{1}{2} T_{1} \log (2 \pi)-\frac{1}{2} \sum_{1}\left(\frac{\left|J\left(t_{i}\right)\right|-x^{\prime}\left(t_{i}\right) \theta}{\sigma\left(t_{i}\right)}\right)^{2} .
\end{gathered}
$$

Let $\Theta_{0}$ be the true vector of parameters and $\hat{\Theta}$ its estimated value. When Newton-like 
maximization method is employed, the negative of the expected inverse Hessian matrix, $V_{H}(\Theta)$, evaluated at $\hat{\Theta}$ is:

$$
V_{H}(\Theta)=-E\left[\frac{\partial^{2} L(\Theta)}{\partial \Theta \partial \Theta^{\prime}}\right]^{-1} \text { at } \Theta=\hat{\Theta}
$$

Under the null hypothesis, $H_{0}: \hat{\Theta}=\Theta_{0}$, the Wald test statistic $\left(\hat{\Theta}-\Theta_{0}\right)^{\prime} V_{H}(\hat{\Theta})\left(\hat{\Theta}-\Theta_{0}\right)$ is asymptotically distributed as a $\mathcal{X}^{2}(k)$, where $k$ is the number of parameters. $V_{H}(\hat{\Theta})$ is the covariance matrix of $\hat{\Theta}$ which contains on its diagonal the estimated variances of the parameters. ${ }^{15}$ Under the null, the Wald statistic for, say, $\beta$, is then:

$$
\mathcal{W}=\frac{\hat{\beta}^{2}}{\widehat{V(\hat{\beta})}} \sim \mathcal{X}^{2}(1) \text {. }
$$

\section{The impact of news announcements on forex returns}

The Tobit-GJR-GARCH estimation results are displayed in Table 3 to Table $6 .{ }^{16}$

\footnotetext{
${ }^{15}$ Alternatively the covariance matrix can be calculated as the outer product of gradients $V_{O P G}(\hat{\Theta})=$ $\frac{1}{N} \sum_{t_{i}} G_{t_{i}}(\hat{\Theta}) G_{t_{i}}(\hat{\Theta})^{\prime}$, where $G_{t_{i}}(\hat{\Theta})=\partial L_{t i}(\Theta) / \partial \Theta$ evaluated at $\Theta=\hat{\Theta}$ and $L_{t i}(\Theta)$ is the loglikelihood at the observation $t_{i}$. It can also be calculated using the so-called Sandwich estimator $V_{S}(\hat{\Theta})=\left[V_{H}(\hat{\Theta})\right]^{-1} V_{O P G}(\hat{\Theta})\left[V_{H}(\hat{\Theta})\right]^{-1}$. Under regularity conditions $V_{H}(\hat{\Theta}), V_{S}(\hat{\Theta})$ and $V_{O P G}(\hat{\Theta})$ are asymptotically equivalent.

${ }^{16}$ Results concerning day-of-the-week effects and intraday periodic effects (FFF) are not reported, but are available upon request to the authors.
} 


\begin{tabular}{|c|c|c|c|c|c|c|c|c|c|c|c|c|}
\hline Macro News & EUR & USD & GBP & USD & JPY & USD & $\overline{\mathrm{CHF}}$ & USD & AUD & USD & CAD & USD \\
\hline & $\lambda^{+}$ & $\lambda^{-}$ & $\lambda^{+}$ & $\lambda^{-}$ & $\lambda^{+}$ & $\lambda^{-}$ & $\lambda^{+}$ & $\lambda^{-}$ & $\lambda^{+}$ & $\lambda^{-}$ & $\lambda^{+}$ & $\lambda^{-}$ \\
\hline $\begin{array}{l}\text { Announcements related to } \\
\text { the Chinese economy }\end{array}$ & & & & & & & & & & & & \\
\hline Monthly New Loan & - & - & - & - & - & - & - & $-20.5^{* * *}$ & - & - & - & - \\
\hline Money Supply M1 & - & - & - & - & - & - & - & $-13.2^{* * *}$ & - & - & - & - \\
\hline Money Supply M2 & - & - & - & 11.07 & - & - & - & $-10.5^{* *}$ & - & - & - & - \\
\hline Retail Sales & - & - & - & - & - & - & - & $-64.9^{* * *}$ & - & - & - & - \\
\hline Value Added of Ind. & - & - & - & - & - & - & - & $-69.7^{* * *}$ & - & - & - & - \\
\hline $\begin{array}{l}\text { Announcements related to } \\
\text { the Euro-Zone economy }\end{array}$ & & & & & & & & & & & & \\
\hline Fixed Assets Inv & - & - & - & - & - & - & - & -3.88 & - & - & - & - \\
\hline M3 Annual Growth & - & - & - & $-445.5^{* * *}$ & - & - & - & - & - & - & - & - \\
\hline Money Supply M3 & - & - & - & $395.1^{* * *}$ & - & - & - & - & - & - & - & - \\
\hline Refinancing Rate & $3.49^{* *}$ & - & - & - & - & - & $3.0 \mathrm{e}-07$ & - & - & - & - & - \\
\hline Unemp. Rate Euro-Zone & - & - & $2.9 \mathrm{e}-07$ & $-87.6^{* * *}$ & - & - & - & - & - & - & - & - \\
\hline $\begin{array}{l}\text { Announcements related to } \\
\text { the Japanese economy }\end{array}$ & & & & & & & & & & & & \\
\hline Merchandise TB & - & - & - & - & - & - & - & - & - & 2.695 & - & - \\
\hline Balance of Payments CA & $2.17 \mathrm{e}-06$ & $20.3^{* * *}$ & - & - & - & - & - & - & - & $31.6^{* * *}$ & - & - \\
\hline Economy Watchers Surv. & - & - & - & - & - & - & - & - & $27.9^{* * *}$ & - & - & - \\
\hline Housing Starts & - & - & $376.3^{* * *}$ & - & - & - & - & - & $125.4^{* * *}$ & - & - & - \\
\hline Industrial Prodction & $45.1^{*}$ & - & $227.3^{* * *}$ & - & - & - & - & - & $37.8^{* *}$ & - & 2.46 & - \\
\hline Loans Discounts Outstand. & $2.17 \mathrm{e}-06$ & $12.4^{* * *}$ & - & - & - & - & - & - & - & - & - & - \\
\hline Machine Orders & -0.88 & $\begin{array}{r}12.4 \\
-\end{array}$ & - & - & - & - & - & - & - & $18.8^{*}$ & - & - \\
\hline Money Stock M2 & $20.2^{* * *}$ & $26.3^{* * *}$ & - & - & - & - & - & - & - & - & - & - \\
\hline Money Stock M3 & $26.1^{* * *}$ & $15.9^{* * *}$ & - & - & - & - & - & - & - & - & - & - \\
\hline Tertiary Industry & - & - & - & - & $59.9^{* * *}$ & - & - & - & - & - & - & - \\
\hline Trade Balance & - & - & - & - & - & - & - & - & - & $15.5^{* * *}$ & - & - \\
\hline $\begin{array}{l}\text { Announcements related to } \\
\text { the U.K. economy }\end{array}$ & & & & & & & & & & & & \\
\hline BoE Official rate PPTA & 0.84 & - & - & - & - & - & $1.4 \mathrm{e}-07$ & - & - & - & $1.7 \mathrm{e}-07$ & - \\
\hline BoE Official rate & $2.1^{*}$ & - & - & - & - & - & $1.4 \mathrm{e}-07$ & - & - & - & $1.7 \mathrm{e}-07$ & - \\
\hline Claimant Count Rate & - & - & $90.9^{* * *}$ & - & - & - & - & - & - & - & - & - \\
\hline CPI Ex Food $\backslash$ Energy & - & - & - & - & - & - & - & - & $23.2^{* * *}$ & - & - & - \\
\hline CPI EU Harmonized & - & - & - & - & - & - & - & - & $-18.7^{* * *}$ & - & - & - \\
\hline GDP & 0.66 & $33.2^{* * *}$ & - & $-126.4^{* * *}$ & - & $-7.23^{* * *}$ & - & - & - & - & - & - \\
\hline HBOS House Prices $3 \mathrm{Mth}$ & - & - & - & $23.8^{* *}$ & - & - & - & - & - & - & - & - \\
\hline PSNCR Net Borrowing & -2.13 & - & - & - & - & - & $27.1^{* * *}$ & - & - & - & - & - \\
\hline PSNCR Public Sector Net & $-51.5 * * *$ & -0.36 & - & - & - & - & - & -8.41 & - & - & - & - \\
\hline RICS UK Wales Housing & - & - & - & - & - & - & - & - & $34.9^{* * *}$ & - & - & - \\
\hline RPI All Items & - & - & - & - & - & - & - & - & $21.7^{* * *}$ & - & - & - \\
\hline RPI less Mortgage Int. & - & - & - & - & - & - & - & - & $-18.2^{* * *}$ & - & - & - \\
\hline Retail Sales Less Auto & $39.9^{* * *}$ & - & - & - & - & - & $26.2^{* * *}$ & - & $47.1^{* * *}$ & - & - & - \\
\hline Trade Balance & - & - & - & - & - & - & $183.6^{* *}$ & - & - & - & - & - \\
\hline ILO Unemp. Rate & - & - & $75.8^{* * *}$ & - & - & - & - & - & - & - & - & - \\
\hline $\begin{array}{l}\text { Announcements related to } \\
\text { the U.S. economy }\end{array}$ & & & & & & & & & & & & \\
\hline Retail Sales Less Auto & _ & _- & _- & _ & $12.4^{* * *}$ & - & $18.5^{* * *}$ & _ & _ & $7.12^{* *}$ & - & $-54.2^{* * *}$ \\
\hline Census Bureau & - & - & - & $-47.3^{* *}$ & 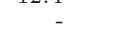 & - & 10.0 & - & - & $14.6^{* * *}$ & - & - \\
\hline Conference Board US Ldg. & $-0.39 * *$ & - & $6.15 \mathrm{e}-07$ & - & $13.3^{* * *}$ & - & 0.00 & - & - & - & - & - \\
\hline Continuing Jobless & $-32.1^{* * *}$ & $152.2^{* * *}$ & - & - & -2.71 & - & $-11.5^{* * *}$ & $-34.6^{* *}$ & $130.0^{* * *}$ & 0.36 & $40.6^{* * *}$ & $-23.8^{* * *}$ \\
\hline CPI Urban C.Less F E & - & - & - & - & - & - & - & - & - & -1.01 & - & - \\
\hline Consumer Price Index & - & - & - & - & - & - & - & - & - & $11.5^{* * *}$ & - & - \\
\hline Capacity Utilisation & 0.20 & $20.1^{* * *}$ & - & $-82.1^{* * *}$ & - & - & 0.49 & -8.48 & - & - & - & $-27.1^{* * *}$ \\
\hline Durable Good Orders Ind. & -20 & $\begin{array}{r}20.1 \\
-\end{array}$ & $273.7^{* * *}$ & $\begin{array}{r}-02.1 \\
-\end{array}$ & - & - & $186.5^{* * *}$ & -0.40 & $39.7^{* * *}$ & - & 9.21 & $\begin{array}{r}-21.1 \\
-\end{array}$ \\
\hline DGO ex Transportation & - & - & -7.08 & - & - & - & $93.9^{* * *}$ & - & 5.46 & - & 2.65 & - \\
\hline Existing Home Sales & - & - & $44.4^{* * *}$ & - & $4.91^{*}$ & - & - & - & $80.5^{* * *}$ & - & $413.6^{* * *}$ & - \\
\hline NonFarm Payrolls & $-3.03^{* *}$ & - & - & - & $5.52^{* *}$ & $-18.7^{* *}$ & $1.80^{*}$ & - & - & - & - & $-22.2^{* * *}$ \\
\hline NFP Manufacturing Ind. & -0.06 & $9.68^{* * *}$ & - & - & 1.97 & $15.4^{* *}$ & - & $-14.5^{* * *}$ & - & - & - & $31.4^{* * *}$ \\
\hline Empire State manuf. Surv. & $-3.41^{*}$ & - & $54.8^{* * *}$ & - & - & - & - & - & - & $14.2^{* *}$ & - & $51.5^{* * *}$ \\
\hline Federal Funds Target Rate & 1.85 & 1.82 & 1.14 & - & - & $-10.8^{* * *}$ & 0.00 & $-6.99^{* * *}$ & - & $6.96^{*}$ & 1.65 & $-5.93^{* * *}$ \\
\hline Foreign Net Transaction & $-32.3^{* * *}$ & $23.1^{* * *}$ & - & -126 & - & - & 1.30 & - & - & - & - & $9.85^{* * *}$ \\
\hline FED Consumer Credit & - & $\begin{array}{r}20.1 \\
-\end{array}$ & - & -120 & - & 5.12 & - & - & - & $34.4^{* * *}$ & - & $-35.9^{* *}$ \\
\hline Initial Jobless Claims & $9.61^{*}$ & $-72.8^{* * *}$ & - & - & $7.82^{* * *}$ & $-7.58^{* * *}$ & $21.0^{* * *}$ & 60.97 & - & $\begin{array}{r}3+.4 \\
-\end{array}$ & $-12.9^{*}$ & $10.6^{* * *}$ \\
\hline Import Price Index & - & - & - & - & - & - & - & - & - & $67.3^{* * *}$ & $25.6^{* * *}$ & $-89.3^{* * *}$ \\
\hline Economic Optimism & - & - & $298.4^{* * *}$ & - & - & - & - & - & $11.9^{* *}$ & - & $9.3^{* * *}$ & - \\
\hline Industrial Production & $17.1^{* * *}$ & - & $152.3^{* * *}$ & - & - & - & 6.84 & 0.19 & - & - & $10.5^{* *}$ & $-18.1^{* * *}$ \\
\hline ISM Manufacturing & - & - & - & - & $-34.2^{* * *}$ & $-13.3^{* * *}$ & - & - & - & - & - & - \\
\hline MNI Chicago Report & - & - & $23.9^{* * *}$ & - & - & $17.5^{* * *}$ & - & - & - & - & - & $-10.7^{* * *}$ \\
\hline Manuf. Trade Invent. & - & - & - & - & - & $-21.8^{* * *}$ & - & $-16.9^{* * *}$ & - & - & - & - \\
\hline Merch. Wholesalers Invent. & - & - & $-84.8^{* * *}$ & - & - & - & - & - & - & $11.9^{* * *}$ & - & - \\
\hline NAHBM Index & $-3.82^{* *}$ & 11.39 & 0.00 & - & - & $-25.7^{* * *}$ & - & - & - & $26.5^{* * *}$ & - & - \\
\hline New One Family Houses & -0.10 & $24.8^{* * *}$ & $349.0^{* * *}$ & - & - & - & - & -17.75 & - & - & - & - \\
\hline New Privately Owned Hsg. & - & - & - & - & $5.65^{* *}$ & - & $13.4^{* * *}$ & - & $-3.18^{* * *}$ & - & 1.18 & - \\
\hline Personal Consumption & - & - & $195.4^{* * *}$ & - & $33.6^{* * *}$ & - & $37.4^{* * *}$ & - & - & - & - & - \\
\hline Private Housing Auth. & - & - & - & - & -2.50 & - & $11.5^{* * *}$ & - & - & $14.1^{* * *}$ & $17.8^{* * *}$ & - \\
\hline Pending Home Sales & - & - & - & $-65.8^{* * *}$ & - & - & - & - & - & - & - & - \\
\hline Private Housing Start. & - & - & - & - & - & - & - & - & - & - & - & $6.43^{* * *}$ \\
\hline Philadelphia Fed Survey & $52.5^{* *}$ & - & $63.4^{* * *}$ & - & $27.3^{* * *}$ & $-36.3^{* * *}$ & $23.1^{* * *}$ & - & - & - & - & - \\
\hline PPI YoY & - & - & - & - & $39.6^{* * *}$ & - & - & - & 2.66 & - & $2.1 \mathrm{e}-07$ & - \\
\hline PPI ex Food $\backslash$ Energy & - & - & - & - & $3.18^{*}$ & - & - & - & 1.45 & - & $2.1 \mathrm{e}-07$ & - \\
\hline PPI Total Goods & _ & _ & - & - & - & $86.9^{* * *}$ & _ & - & - & - & - & $32.0^{* * *}$ \\
\hline PPI Total Goods YoY & _ & _ & - & _ & - & - & _ & - & $3.88^{* *}$ & - & - & - \\
\hline Private Total Housing Auth. & - & - & - & - & - & - & - & - & 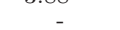 & - & $6.62^{*}$ & - \\
\hline Trade Balance & - & - & - & - & - & -5.06 & - & $-33.8^{* *}$ & - & $5.11^{* * *}$ & 10.02 & 2.89 \\
\hline Treasury FED Budget Debt & $-90.7^{* * *}$ & $12.7^{* * *}$ & - & $-33.1^{*}$ & - & $-16.9^{* * *}$ & - & - & - & $11.2^{* *}$ & - & $-9.58^{* * *}$ \\
\hline Univ. Michigan Cons Sentim. & - & - & - & - & $-17.7^{* * *}$ & - & - & $-442.2^{* *}$ & - & - & $-3.56^{* *}$ & - \\
\hline Unemp. Rate & - & $4.93^{* * *}$ & - & - & -6.04 & $6.10^{* * *}$ & $-2.97^{*}$ & - & - & - & $48.1^{* * *}$ & - \\
\hline Unemp. Rate Seas. Adj. & - & $5.16^{* * *}$ & - & - & - & - & - & - & - & - & - & - \\
\hline
\end{tabular}

Note : The estimated parameters are those of the component $\lambda(t i)$ given by equation (16). A hyphen (-) indicates that the news does not match with a jump and therefore is not included in the regression. $(*),(* *)$ and $(* * *)$ denote significance at the $10 \%, 5 \%$ and $1 \%$ levels of significance, respectively.

Table 3: Estimation of the Tobit-GJR-GARCH model : Scheduled Announcements 
Table 3 presents the results related to the impacts of surprises from scheduled macroeconomic announcements on the absolute significant returns of our six currencies. ${ }^{17}$ First, it can be seen that among the 78 surprises considered, 18 of them affect three currencies at a time and 6 of them impact four currencies at a time at the $5 \%$ level. Because all our exchange rates are denominated against the dollar, most of these 24 significant surprises are related to the U.S. economy. The six most influential surprises (i.e. those that impact four exchange rates at a time) come from continuing jobless claims, initial jobless claims, nonfarm payrolls in manufacturing industries, retail sales (less automobiles), the Philadelphia Fed survey and the Treasury Federal budget debt.

Initial and continuing jobless claims and nonfarm payrolls impact exchange rate volatility because an increase in initial and continuing claims and a decrease in nonfarm payrolls are obvious signs of reduction in employment opportunities and therefore of weakening of the economy. If the US economy enters a recession, one would expect interest rates to fall which, in turn, would make US assets less attractive for foreign investors and depreciate the dollar. These employment situation reports are the most internationally followed U.S. figures because they reflect all major sectors of the economy (production, income, consumption), besides the fact that they are related to U.S. monetary policy: since the last recession, the employment situation drives the "quantitative easing" decisions of the FED. Moreover, as they are the earliest indicators of economic trends published each month, employment announcements can trigger very large movements in FX markets.

Investors focus also on retail sales because these are good predictors of GDP as retail market helps them to spot specific investment opportunities, without having to wait for a company's quarterly or annual report. They monitor the Philadelphia Federal survey because it is viewed as an indicator of the evolution of the manufacturing sector. As for the relationship between news on Federal public debt and the exchange rate of the dollar, a large debt impacts exchange rate if foreign investors believe that the country risks defaulting on its debt and therefore sell the dollar denominated bonds they hold, producing a depreciation of the dollar.

The 18 news which significantly impact only three exchange rates include: the industrial production, personal consumption expenditure capacity utilization, the Empire State Manufacturing survey, the Federal Fund's target rate, housing market news (NAHBM Index), and the new privately owned housing. The latter provides to investors information about new home sales or resales and, through a "ripple effect", all required housing equip-

\footnotetext{
${ }^{17}$ Note that a number of coefficients are negative whereas the specification in absolute value of the dependent variable and of the negative surprises in Equation 16 suggests that the coefficients $\lambda^{+}$and $\lambda^{-}$are positive. Such a result may potentially stem from the fact that surprises based on concomitant announcements are measured with errors. Indeed, representing market forecasts by median survey forecasts in calculating surprises may lead to measurement errors on market forecasts or, equivalently, on surprises (Lahaye et al. (2011)). While a measurement error on a single variable is known to imply an attenuation bias (the estimate shrinks towards zero), in the multivariate case the direction of bias is undetermined. Simultaneously, the existence of concurrent announcements at the time of a jump may lead to select several significant surprises with measurement errors, while the estimated model may include one or several negative surprise effect(s) to offset a positive total bias. However, the central issue we are concerned with is not to know the values of the estimated parameters but simply to identify the significant surprises in explaining jumps.
} 
ment. It also reflects the consumer confidence about the future of the economy. The US Federal Funds target rate is announced by the US Federal Open Market Committee (FOMC) and has direct and immediate impact on financial markets since it is considered as a good indicator of monetary policy and a particularly informative nominal interest rate for future real economic variables (Bernanke \& Blinder 1992).

We also find that, apart the US variables, GDP and retail sales from UK affect the Euro, the Pound end the Yen. Note that the Swiss Franc is the only currency influenced by all the Chinese announcements. This result is likely related to the historical economic relationship between the two countries. In fact, Swiss firms have been investing in China substantially over the last decade. Swiss banks were among the first Western banks to establish correspondent banking relationships with Chinese banks. Switzerland is also the first country on the European continent that has signed a Free Trade Agreement with China. ${ }^{18}$

Depending on whether its coefficient is reported in the $\lambda^{+}$or $\lambda^{-}$column under each exchange rate, a news can take the form of a positive or negative surprise. A positive surprise means that the underlying announcement has been underestimated, while a negative surprise reflects an overestimated announcement. Depending on the nature of the announcement, an under- or overestimation of its future value can be viewed either as good news or as bad news. For example, negative (positive) surprises on initial and continuing jobless claims and on public debt are good (bad) news because they imply that reality is better (worse) than expected. This reflects that survey respondents tended to make pessimistic (optimistic) forecasts. Similarly, positive (negative) surprises on retail sales, nonfarm payrolls and Philadelphia Fed survey are good (bad) news. It is noteworthy that both Treasury debt and Philadelphia Fed survey impact exchange rate volatility as good news for most of the currencies. As for nonfarm payrolls, they influence all exchange rates as bad news as a result of optimistic forecasts. Turning to our 24 news that significantly impact at least half of our currency panel, our results show that in $59 \%$ of cases financial traders report good news with respect to their forecasts when announcements are released. This can be explained by the fact that during the crisis period analyzed (2007-2012), they were more often delivering pessimistic forecasts. The asymmetry between good and bad news is particularly pronounced for news concerning agents' sentiment on economic health, ${ }^{19}$ public debt and housing, ${ }^{20}$ for which the proportions of good news are $83 \%, 80 \%$ and 77\%, respectively. These findings seem consistent with Andersen et al. (2003) result that "bad news in good times have greater impacts than good news in good times".

\footnotetext{
${ }^{18}$ Source : http://www.swissbanking.org/home/dossiers-link/renminbi.htm

${ }^{19}$ The underlying news are: Economic optimism Index and University of Michigan Consumer Sentiment Index.

${ }^{20}$ The underlying news are: Existing home sales, NAHB Index, New privately owned housing and Private housing authorized.
} 


\begin{tabular}{|c|c|c|c|c|c|c|c|}
\hline Date & Unanticipated News & 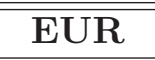 & GBP & JPY & CHF & AUD & CAD \\
\hline $12 / 12 / 2007$ & FOMC Board TAF & - & - & - & - & 2.68 & - \\
\hline $12 / 12 / 2007$ & $20 \mathrm{~B} \$$ to the ECB and $4 \mathrm{~B} \$$ to SNB & - & - & - & - & 2.68 & - \\
\hline $04 / 01 / 2008$ & Bush Paulson meeting with WGFM & - & - & - & - & - & $-20.8^{*}$ \\
\hline $22 / 01 / 2008$ & FED cut interest rate by $75 \mathrm{bpt}$ & - & - & $19.0^{* * *}$ & - & - & - \\
\hline $14 / 03 / 2008$ & Bear Stearns near collapse & - & - & $9.72^{* * *}$ & -3.83 & - & - \\
\hline $17 / 03 / 2008$ & B.Stearns acquisition for $240 \mathrm{M} \$$ & - & - & $13.6^{* * *}$ & $14.7^{* * *}$ & - & - \\
\hline $22 / 04 / 2008$ & BoE acquire UK bank's mortg-backed & - & - & - & - & - & $-10.5^{* * *}$ \\
\hline $15 / 09 / 2008$ & Lehman Broth. Bankruptcy & $-14.6^{* * *}$ & $-44.8^{* * *}$ & - & $-13.5^{* * *}$ & $9.08^{*}$ & $-9.24^{* * *}$ \\
\hline $29 / 09 / 2008$ & 700B $\$$ Bailout Plan & $-11.8^{* * *}$ & $-69.8^{* * *}$ & - & $13.4^{* * *}$ & $12.3^{* *}$ & 4.24 \\
\hline $13 / 10 / 2008$ & Dutch Credit 500B $\$$ Bailout Plan & - & $-190^{* * *}$ & - & - & 9.16 & - \\
\hline $17 / 10 / 2008$ & The EU 2.7T $\$$ bailout plan & - & 7.33 & - & - & -0.25 & - \\
\hline $20 / 10 / 2008$ & French Gov -10.5B $\$$ Bailout Plan & $-15.1^{* * *}$ & $193^{* * *}$ & - & - & - & $-19.8^{* * *}$ \\
\hline $27 / 10 / 2008$ & Iceland's Kaupthing Bank Defaults & $-16.6^{* * *}$ & 6.74 & $30.7^{* * *}$ & $-158^{* * *}$ & $13.0^{*}$ & 0.82 \\
\hline $09 / 11 / 2008$ & AIG 150B $\$$ Bailout Plan & - & $-68.4^{* * *}$ & - & - & $8.95^{*}$ & 7.83 \\
\hline $14 / 11 / 2008$ & Freddie Mac- 13.8B $\$$ losses & $10.9^{* *}$ & $72.1^{* * *}$ & - & - & 5.98 & 6.34 \\
\hline 09/12/2008 & 12 Banks Lowered by SP & - & $-135^{* * *}$ & - & - & - & $-158^{* * *}$ \\
\hline $11 / 12 / 2008$ & Bernard Madoff fraud & - & $61.2^{* * *}$ & $-7.79^{* * *}$ & - & 3.15 & $168^{* * *}$ \\
\hline $14 / 01 / 2009$ & SP500 cuts Greece's credit rating on debt & - & $-189^{* * *}$ & - & - & $14.8^{* * *}$ & $-221^{* * *}$ \\
\hline $15 / 01 / 2009$ & US gov. 138B $\$$ bailout to BofA & - & $57.2^{* * *}$ & - & - & - & $-70.6^{* * *}$ \\
\hline $19 / 01 / 2009$ & SP 500 slashes Spain's triple A rating & - & $205^{* * *}$ & - & - & - & - \\
\hline $20 / 01 / 2009$ & 1st election of Barack $\mathrm{O}$. & $-17.4^{* * *}$ & $171^{* * *}$ & $21.9^{* * *}$ & - & - & - \\
\hline $27 / 01 / 2009$ & Japan announces a 16.7B $\$$ stimulus & - & $-124^{* * *}$ & - & - & - & - \\
\hline $12 / 03 / 2009$ & Japan 1.2B $\$$ Bailout Plan & - & - & 0.13 & $18.4^{* * *}$ & - & - \\
\hline $20 / 04 / 2010$ & BP Oil Spill spewed into the GoMex. & - & - & - & - & - & $12.2^{* * *}$ \\
\hline $11 / 03 / 2011$ & Japan earthquake and Tsunami & - & - & $-9.40^{* * *}$ & - & - & - \\
\hline 06/09/2011 & SNB sets min ER at CHF 1.20 per $€$ & - & - & - & $18.8^{* * *}$ & - & - \\
\hline $27 / 10 / 2011$ & EU. leaders-rescue Greece & - & - & $5.16^{* * *}$ & - & - & - \\
\hline
\end{tabular}

Note: A hyphen (-) indicates that the news does not match with a jump and therefore is not included in the regression.

$(*),(* *)$ and $(* * *)$ denote significance at the $10 \%, 5 \%$ and $1 \%$ levels of significance, respectively.

Table 4: Estimation of the Tobit-GJR-GARCH model : Unscheduled Announcements

As regards the unscheduled news coefficients, it seems that all our currencies except the Yen are primarily affected by the Lehman Brothers bankruptcy and, in some extent, by the 700B \$US bailout plan allowed under the Troubled Asset Relief Program, which both occurred in September 2008. Iceland's Kaupthing bank defaults, the French Government bailout plan, Standard \& Poor's decision to downgrade Greece, the first Barack Obama's election and the Madoff fraud are the major other events that impacted many currencies. The EUR/USD was affected by most of the events mentioned above and by Freddie Mac loss releases of 14/11/2008. Jumps in GBP/USD exchange rate were mostly provoked by all events documented above and by many bailout plans (EESA, AIC, Dutch Credit, EU, Us Government) and downgrading announcements (Greece, Spain). The Japanese Yen was not directly hit by the crisis, but was sensitive to Obama's 2009 election, to the Japanese earthquake and Tsunami occurred on March 2011 while the Swiss Franc was subject to the high devaluation plan conducted by the Swiss National Bank. The Australian Dollar was only affected by the US bailout plan and downgrade of Greece's rating. 


\begin{tabular}{ccccccc}
\hline \hline Coeff & EUR & GBP & \multicolumn{1}{c}{ JPY } & \multicolumn{1}{c}{ CHF } & AUD & CAD \\
\hline$\omega$ & $0.15^{*}$ & $1.50^{* *}$ & $10.24^{* * *}$ & $17.09^{* * *}$ & $0.23^{* *}$ & $0.15^{* *}$ \\
$\alpha$ & $0.03^{* * *}$ & $0.05^{* * *}$ & $0.26^{* * *}$ & $0.19^{* * *}$ & $0.05^{* * *}$ & $0.04^{* * *}$ \\
$\gamma$ & $0.021^{*}$ & $0.021^{*}$ & $0.56^{* * *}$ & $0.24^{* *}$ & 0.02 & 0.02 \\
$\beta$ & $0.95^{* * *}$ & $0.93^{* * *}$ & 0.11 & $0.64^{* * *}$ & $0.93^{* * *}$ & $0.94^{* * *}$ \\
\hline \hline $\begin{array}{l}\text { Note: } \\
\text { tively. }\end{array}$
\end{tabular}

Table 5: Estimation of the Tobit-GJR-GARCH model : the GJR-GARCH

Table 5 displays the estimation results of the GJR-GARCH part of our model. The stationarity condition is satisfied for all currencies. As explained above if the leverage coefficient is non-zero in Equation (23), then positive and negative shocks exert asymmetric effects on volatility. Our results strongly support the presence of asymmetric effects for the Japanese Yen and the Swiss franc at the $5 \%$ level of significance and for the Pound and the Euro at the $10 \%$ level (note that $\beta$ is not significant for JPY/USD exchange rate, suggesting that a GJR-ARCH would more adequately fit the volatility for this currency). By contrast, there is no asymmetry for the Australian Dollar and Canadian Dollar, implying that a Tobit-GARCH model would be more appropriate for these two currencies.

It is worth noting that a greater effect of a negative past return in a foreign exchange market cannot be interpreted as straightforwardly as in the stock markets where, following Black (1976), a drop in the stock price of a firm would imply a rise in its leverage and this bad news would in turn lead to an increase in the volatility (leverage effect). Such negative shocks, called "bad news", are then believed to generate larger volatility than positive shocks or "good news". It is hard to define what are "good" and "bad" news in the case of changes in exchange rates (see maya 2008, for an attempt). In fact, the definition is likely to depend upon whether the economy experiences good or bad times (Andersen et al. (2003)). In a boom, appreciation can serve to reduce inflation and can therefore be qualified as good news. In a recession, good news would rather be a depreciation which helps to improve competitiveness and increase exports. Our results do not allow for an interpretation in terms of good or bad news because our jumps are expressed in absolute value and therefore are not informative about the direction of the change in exchange rate. However, the hypothesis that negative volatility shocks have a larger impact on volatility than positive ones is validated by our results and translates as follows. While a foreign exchange jump with a higher-than-expected absolute magnitude (positive residual) reflects capital flows seeking safe haven currencies during the crisis period, a jump with a lowerthan-expected absolute magnitude (negative residual) may be viewed as the consequence of an effective intervention policy conducted by the central bank in order to avoid large changes in exchange rates. However, such a stabilizing policy is costly, since it generates transaction costs, international trading costs or risk management costs. Indeed, in the short run central banks bear stabilization policy costs that are all the larger that return volatility is high. Being subject to these costs is interpreted by the market as an undesirable side effect and leads to a volatility response greater than the volatility response due to arbitrage movements in foreign exchange markets. 
Overall, our results show that exchange rate jumps residuals exhibit conditional variances that are asymmetric for the most leading world currencies. Ignoring this feature would bias the results and give misleading estimates.

\begin{tabular}{|c|c|c|c|c|c|c|}
\hline & EUR & $\overline{~ G B P}$ & $\overline{~ J P Y ~}$ & $\overline{\mathrm{CHF}}$ & $\overline{\text { AUD }}$ & $\overline{\mathrm{CAD}}$ \\
\hline$A I C$ & 3.7321 & 6.9088 & 4.0931 & 5.7654 & 4.5324 & 3.7397 \\
\hline$B I C$ & 3.7597 & 6.9395 & 4.1218 & 5.7913 & 4.5593 & 3.7673 \\
\hline$L L f$ & 1034272 & 907742 & 1004892 & 1138459 & 1690758 & 1327704 \\
\hline$L L r$ & 1036411 & 910038 & 1006191 & 1138546 & 1691794 & 1328660 \\
\hline
\end{tabular}

Table 6: Estimation of the Tobit-GJR-GARCH model: Information Criteria and Loglikelihood values

Table 6 displays the values of the log-likelihood associated with the full Tobit-GJRGARCH model (LLf) and given by Equation (27) and the values of the log-likelihood associated with the restricted Tobit-GJR-GARCH model $(L L r)$ where the surprises on scheduled announcements (16) and unscheduled events (17) have been removed from the Tobit model which thus only comprises intraweek (18) and intraday (19) periodicities. For each of the currencies, to check that our two categories of news improve significantly the jump model, we compute the likelihood ratio statistic $\mathcal{L}=2(L L r-L L f)$ which compare to a $\mathcal{X}^{2}$ with $33,35,32,29,30$ and 32 d.o.f., respectively. We find that news contribute very significantly to explain jumps in each foreign exchange market.

\section{Conclusion}

This paper studies the effects of two categories of news, scheduled macroeconomic announcements and unscheduled event releases, on jumps in six foreign exchange markets (Euro, Pound, Yen, Australian dollar, Canadian Dollar and Swiss franc, all against the U.S dollar). To this end, we first use an innovative non parametric test procedure suggested by Lee and Mykland (2012) allowing to detect significant jumps in equilibrium prices after removing microstructural noise from observed prices. Test results suggest that the Pound and the Yen have more microstructure noise than the other forex rates, since the denoising frequency is higher for these two exchange rates (126 min vs $102 \mathrm{~min}$ ). About $0.41 \%$ of all denoised returns represent significant jumps, which is a higher proportion of jumps than in previous studies where the denoising frequency is determined by simulations. Using these denoised data we find that our scheduled macro news and unscheduled event releases match with about $34 \%$ and $14 \%$ of total jumps, respectively. These empirical findings point out the relevance of removing microstructure noise before applying a jump detection test. Turning to model specification, our discontinuous (censored) high-frequency 
jump data justifies the use of a Tobit model with heteroskedastic structure of residuals. Further, to test for the stylized fact that negative volatility shocks increase volatility by a greater amount than positive shocks, we specify a Tobit-GJR-GARCH model. In line with other results in the literature, we find that news impact volatility significantly. Scheduled macroeconomic surprises affect foreign exchange returns in the form of good news with a proportion of $59 \%$, reflecting rather pessimistic forecasts from traders during the crisis period analyzed. The macro surprises that exert a common impact to a majority of exchange rate jumps are related to initial and continuing jobless claims, nonfarm payrolls in manufacturing industries, retail sales, the Philadelphia Fed survey and the Treasury Federal budget debt. Concerning the unscheduled event releases, the Lehman Brothers bankruptcy and EESA bailout plan come as the most influential shocks. We also find that jump responses are characterized by a significant asymmetry in negative and positive volatility shocks for most of the major currencies considered, suggesting that markets are sensitive to the costs implied by central banks' stabilization policies. 


\section{APPENDIX}

APPENDIX 1 : Jumps around some scheduled macroeconomic announcements

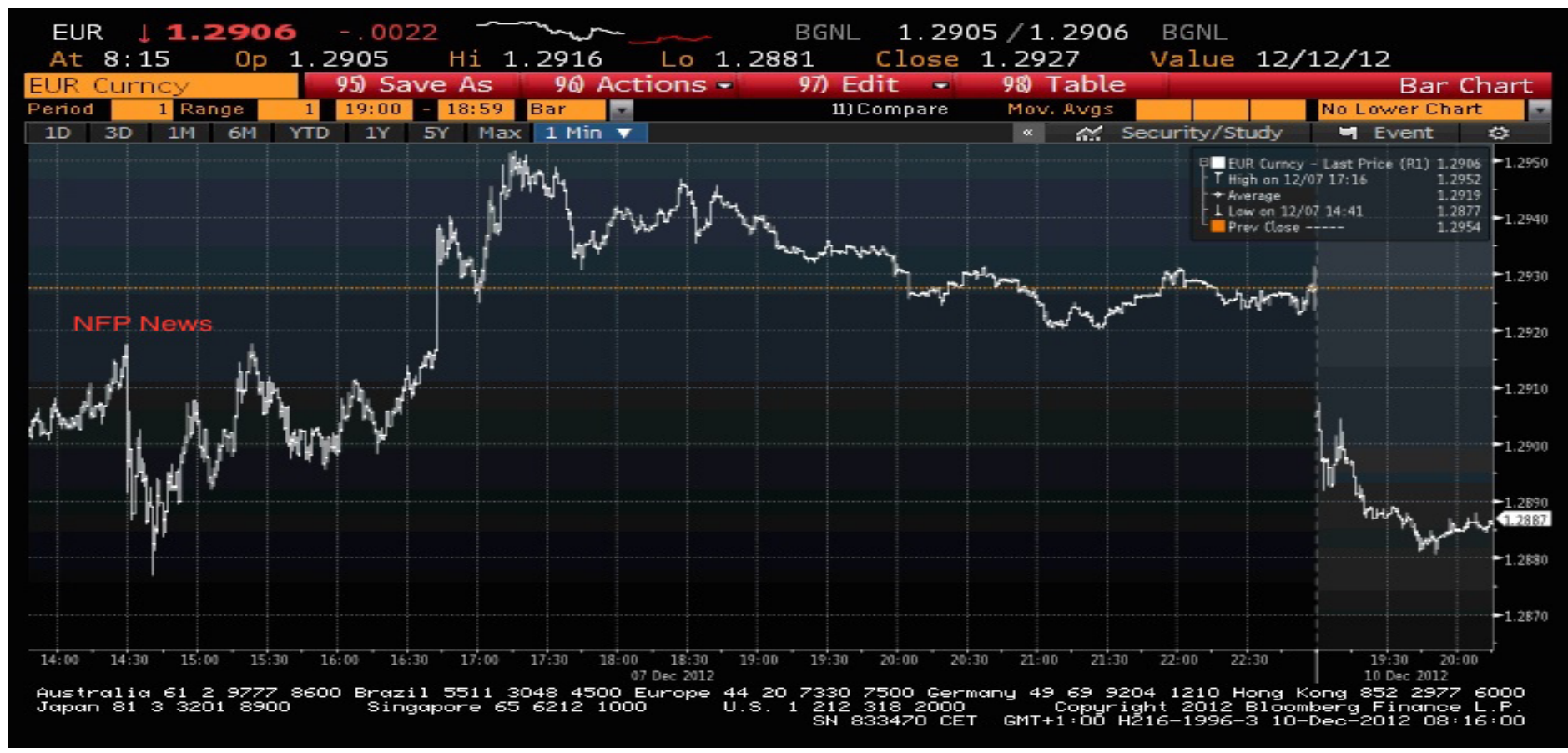

Figure (a): EUR/USD around NFP announcement - 2012/12/07 - 13:30

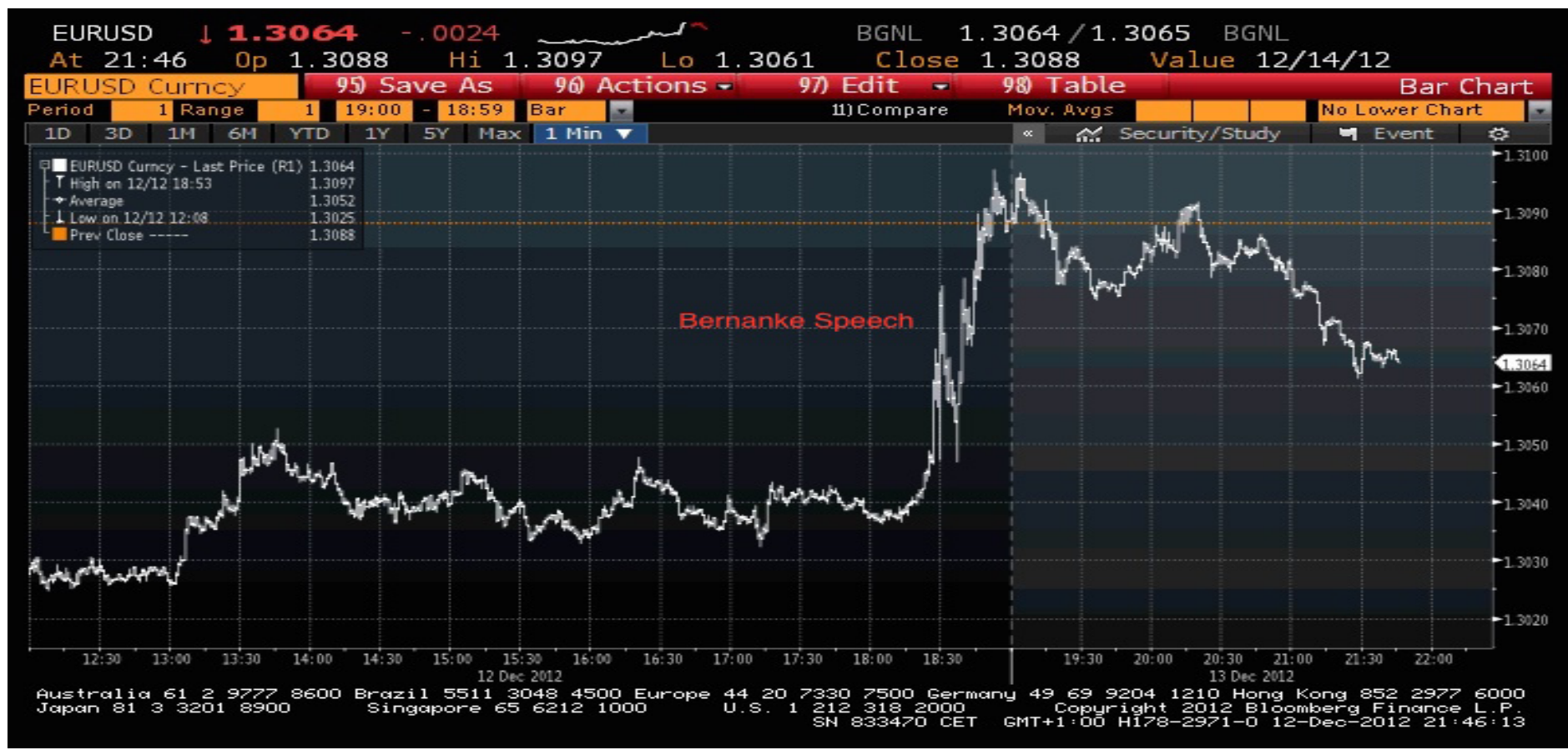

Figure (b): EUR/USD around federal target rate announcement - 2012/12/12 - 18:30 


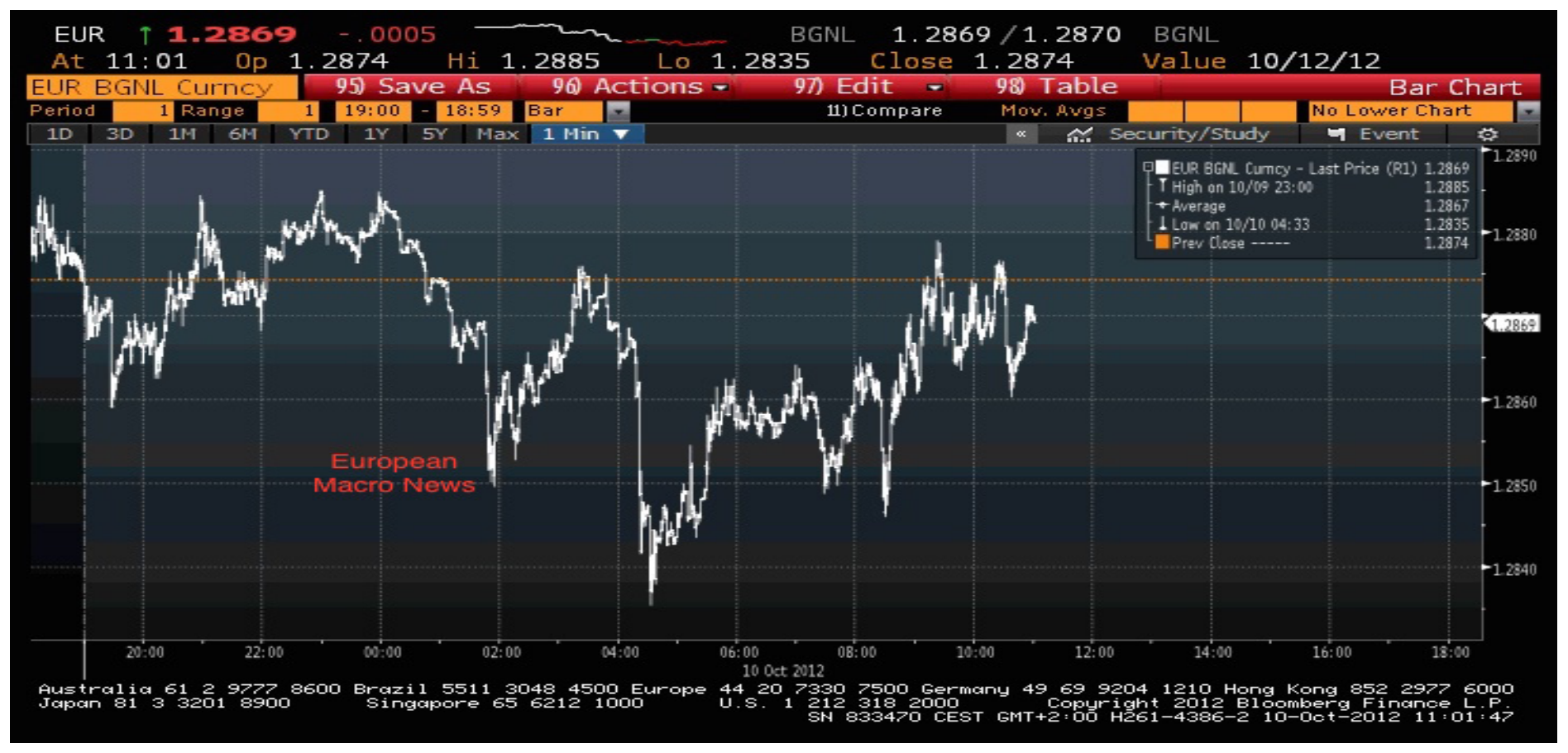

Figure (c): EUR/USD around aggregate european macro announcement - 2012/10/10 - 01:45

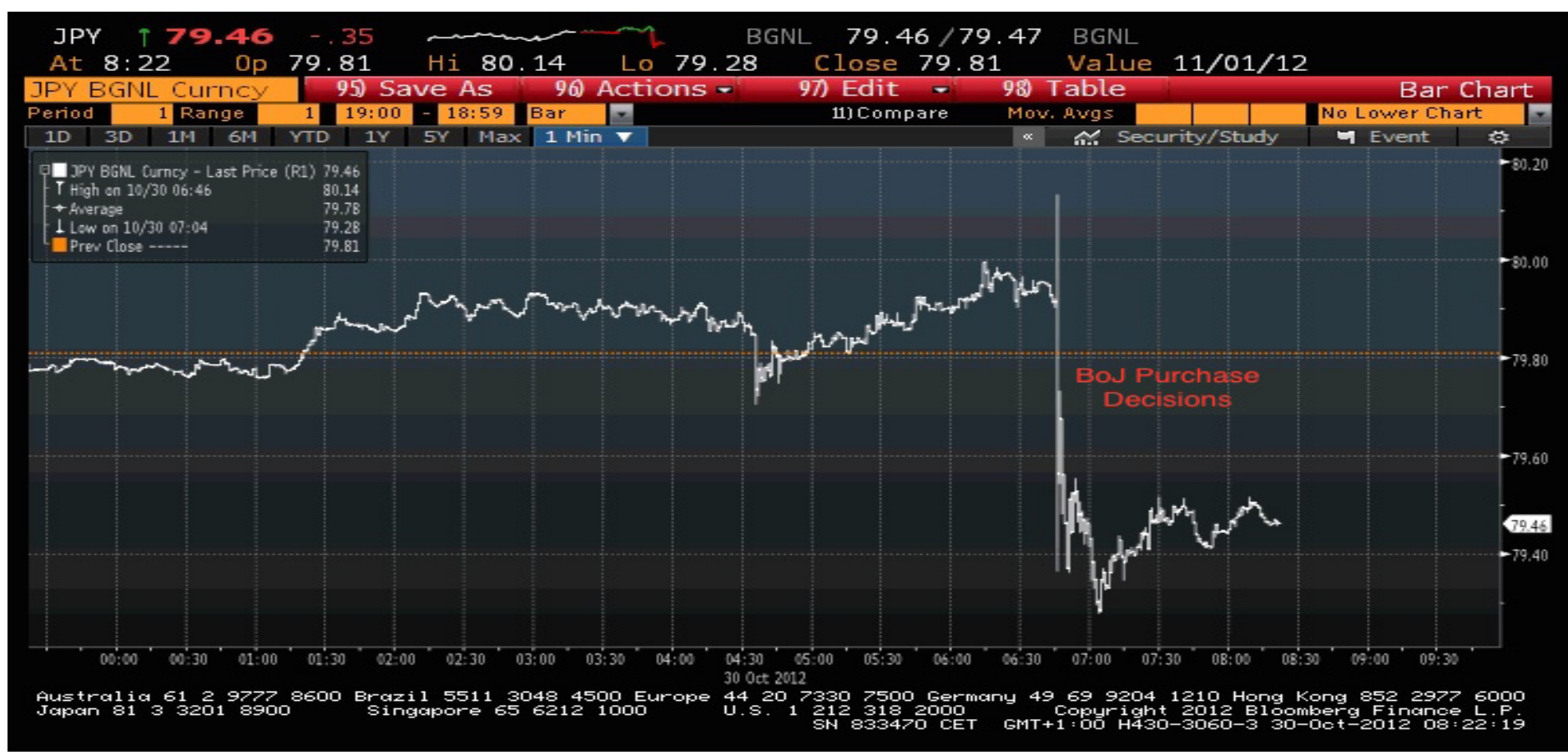

Figure (d): JPY/USD around Bank of Japan assets purchase decision announcement - 2012/10/30 - 06:45 


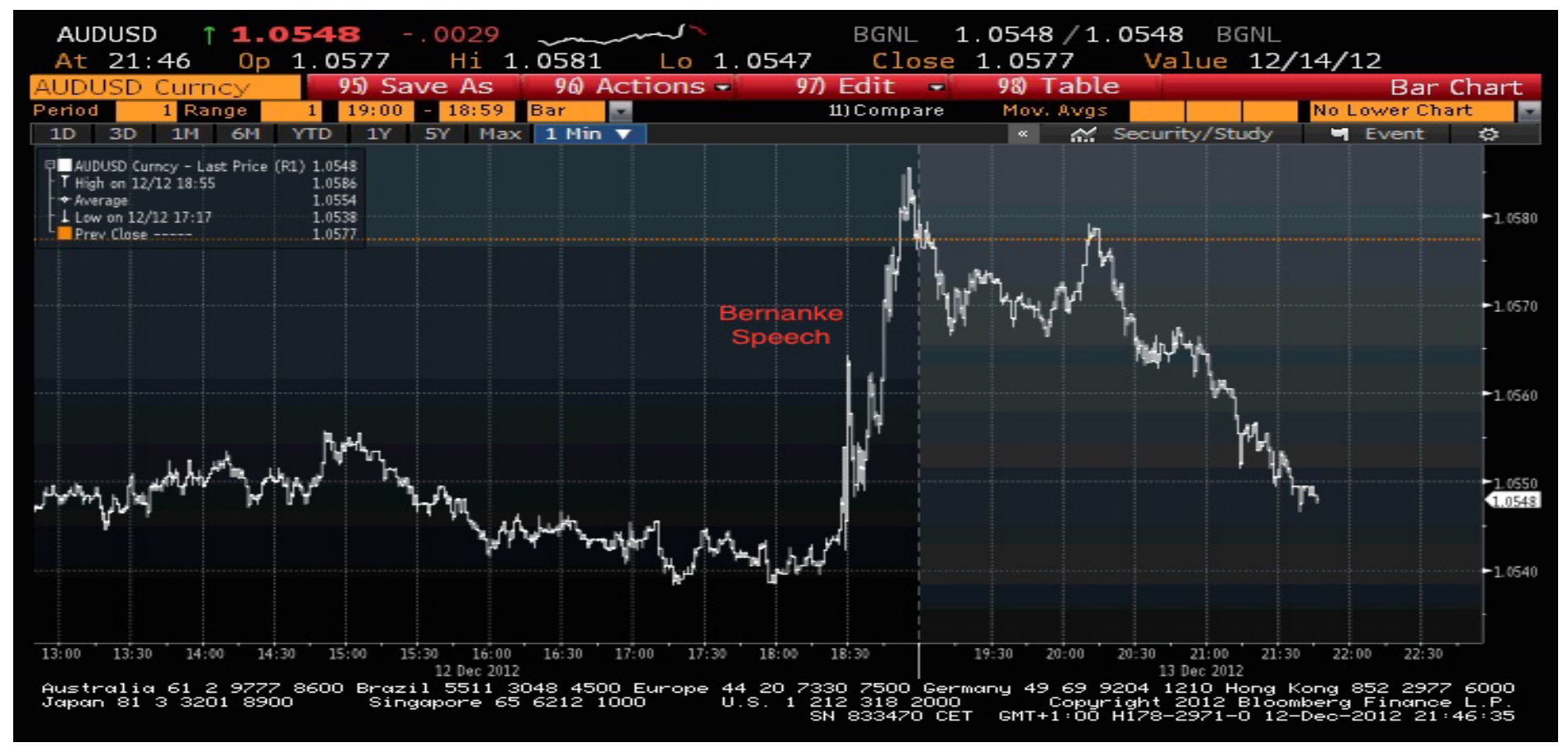

Figure (e): AUD/USD around federal target rate announcement - 2012/12/12 - 18:30

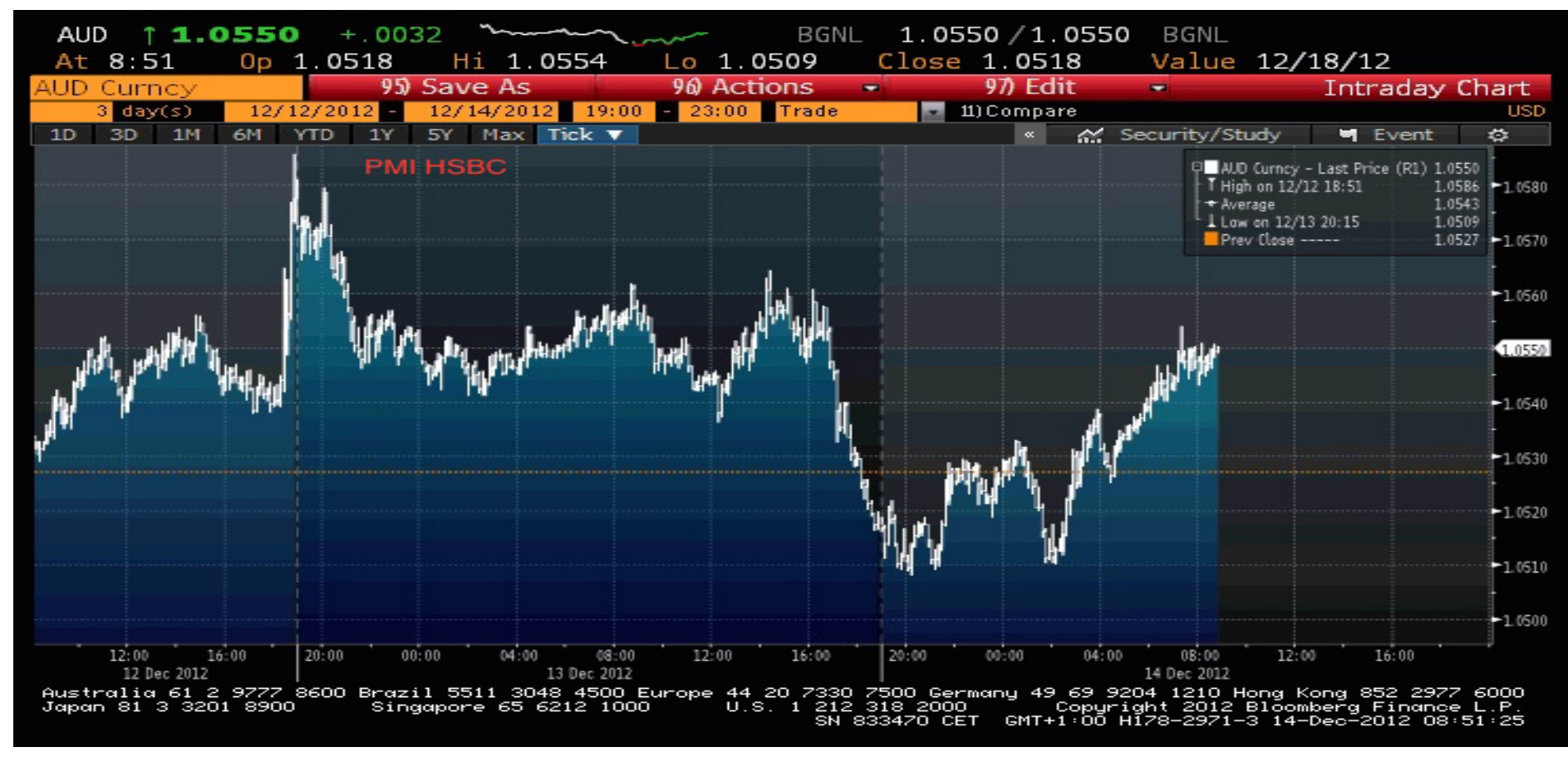

Figure (f): AUD/USD around HSBC PMI announcement - 2012/12/12 - 06:00 
APPENDIX 2 : Jumps around some unscheduled event news
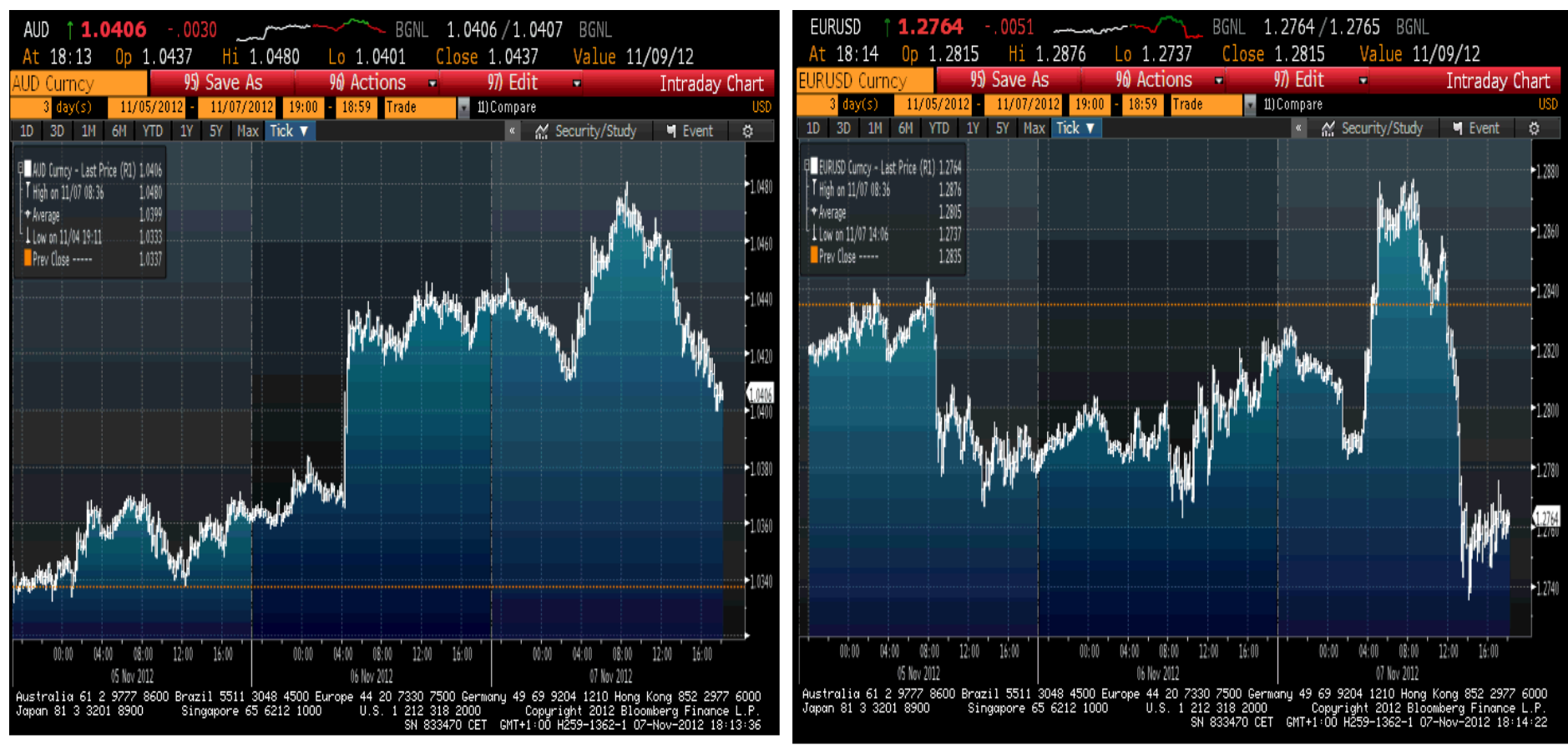

Figure (a): Jumps around U.S. elections: AUD/USD (left panel) and EUR/USD (right panel)

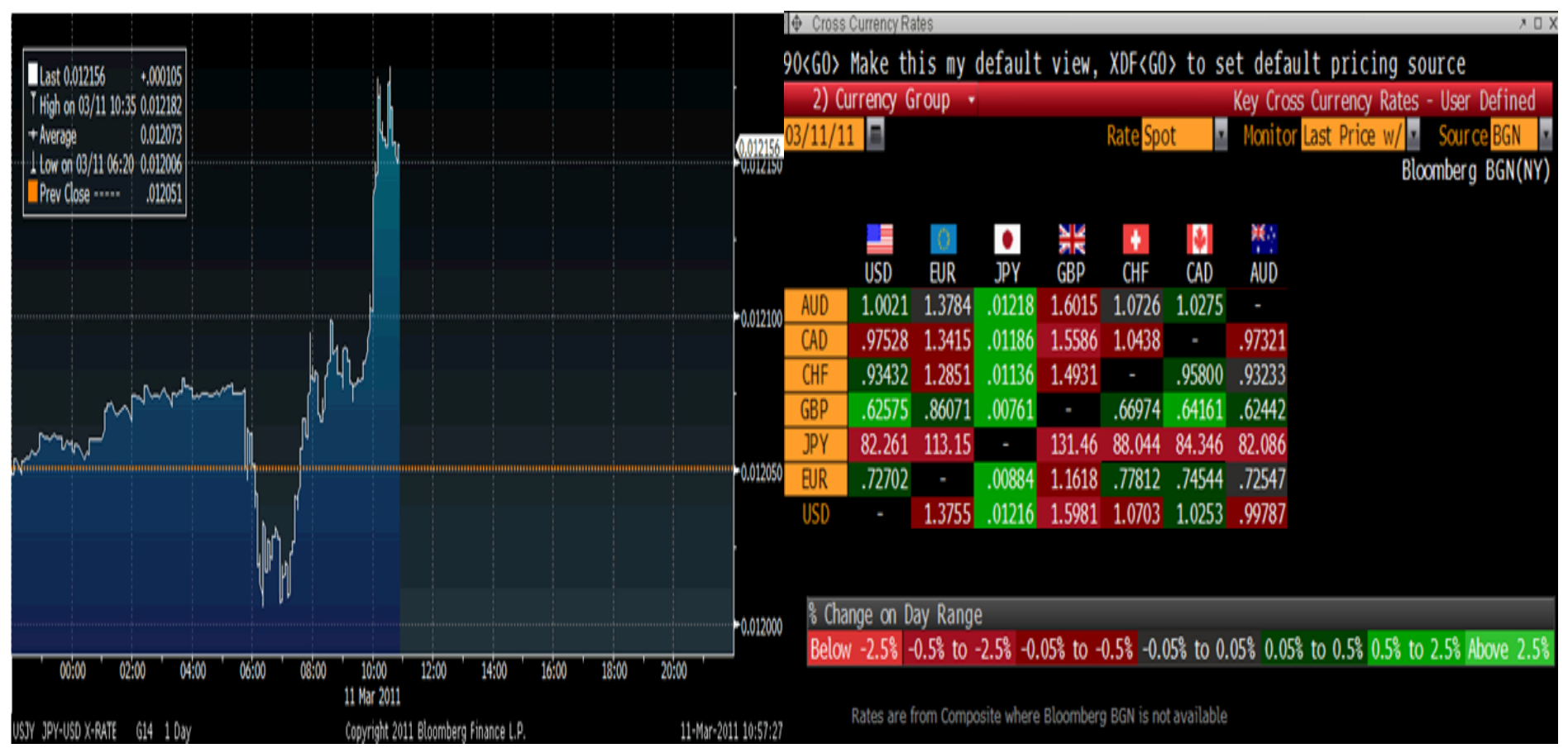

Figure (b): The effect of the Japanese earthquake: the JPY/USD (left panel) and the forex market (right panel) 


\section{APPENDIX 3 : Macroeconomic news announcements}

\begin{tabular}{|c|c|c|c|c|}
\hline Type of announcement & Variable name & Release time & Reporting convention & Source \\
\hline \multicolumn{5}{|c|}{ Activity Indicators } \\
\hline Philadelphia Federal Index & PHIL & $15: 00$ & Value & Philadelphia FDR \\
\hline Industrial Production & IP & $14: 15$ & Rate / \% & Federal Reserve \\
\hline Durable Goods Orders & DGO & $13: 30$ & Rate / \% Change & U.S. Census Bureau \\
\hline Factory Orders & FO & $15: 00$ & Rate /\% Change & U.S. Census Bureau \\
\hline ISM Manufacturing & ISM & 15:00 & Value / S.A. & ISM \\
\hline Empire State Manufacturing Survey & ESMS & $13: 30$ & Value / S.A. & FED of New York \\
\hline MNI Chicago Report & MNCR & $14: 45$ & Value S.A. & MNI DBG \\
\hline IBD-TIPP Index of Economic Optimism & IEO & $15: 00$ & Value / S.A. & IBD and TMI \\
\hline \multicolumn{5}{|c|}{ Consumption and Employment Indicators } \\
\hline Univ. of Michigan-Consumer Confidence Sentiment & $\mathrm{MCCF}$ & $15: 00$ & Rate / S.A./ $1985=100$ & Reuters and Univ. of Michigan \\
\hline Federal Reserve Consumer Credit & $\mathrm{CCD}$ & 20:00 & Value / Billions & Federal Reserve \\
\hline Retail Sales less auto & RSLA & $13: 30$ & Rate / \% Change & U.S. Census Bureau \\
\hline Non-farm Payrolls Total MoM & NFP & $13: 30$ & Value/Thousands & BLS \\
\hline Non-farm Payrolls Manufacturing Industry & NFP & $13: 30$ & Value/Thousands & BLS \\
\hline Personal Spending Core Price Index & $\mathrm{PCE}$ & $13: 30$ & Rate / \% Change & BEA \\
\hline Unemployment rates & UP & $13: 30$ & Rate / \% & BLS \\
\hline Continuing Jobless and Initial Jobless Claims QoQ & CJC and IJC & $13: 30$ & Rate /\% & BLS \\
\hline \multicolumn{5}{|c|}{ Property Indicators } \\
\hline NAHBM Index & NAHBM & $15: 00$ & Volume / Thousands & U.S. NAHB \\
\hline Existing Homes Sales & EHS & $15: 00$ & Volume / Thousands & NAR \\
\hline Pending Home Sales Index & PHS & $15: 00$ & Volume / Thousands & NAR \\
\hline \multirow{2}{*}{\multicolumn{5}{|c|}{ Inflation Indicators }} \\
\hline & & & & \\
\hline Producer Price Index & PPI & $13: 30$ & Rate / \% Change & BLS \\
\hline Consumer Price Index & CPI & $13: 30$ & Rate /\% Change & BLS \\
\hline PPI Ex Food and Energy & PPIC & $13: 30$ & Rate /\% Change & BLS \\
\hline CPI Ex Food and Energy & CPIC & $13: 30$ & Rate /\% Change & BLS \\
\hline \multicolumn{5}{|c|}{ Monetary Policy Indicators } \\
\hline Federal Funds Target Rate & FFRT & $19: 15$ & Value / Billions & FED of New York \\
\hline Treasury Federal Budget Debt & TFBDSD & 19:00 & Value / Billions & U.S. Treasury \\
\hline \multicolumn{5}{|c|}{ Foreign Trade Indicators } \\
\hline Trade Balance & TB & $13: 30$ & Value / Billions & U.S. Census Bureau \\
\hline Merchant Wholesalers Inventories Total & MWI & $15: 00$ & Value / Billions & U.S. Census Bureau \\
\hline Foreign Net Transactions & FNT & $14: 00$ & Value / Millions & U.S. DoT \\
\hline Import Price Index & IPI & $13: 30$ & Value / Billions & U.S. Census Bureau \\
\hline
\end{tabular}

Table (a): United States (U.S.)

\begin{tabular}{|c|c|c|c|c|}
\hline Type of announcement & Variable name & Release time & Reporting convention & Source \\
\hline \multicolumn{5}{|c|}{ Activity Indicators } \\
\hline Chained GDP at Market Prices QoQ & GDP & $08: 30$ & Rate / \% Change & ONS \\
\hline \multicolumn{5}{|c|}{ Property Indicators } \\
\hline HBOS House Prices 3 Mth YoY & HBOS & $7: 00$ & Value / & Halifax and BoS \\
\hline RICS England and Wales housing Market Survey & RICSWHM & 23:01 & Value/ & RICS \\
\hline \multicolumn{5}{|c|}{ Consumption and Employment Indicators } \\
\hline RPI Less Mortgage Interest Payments & RPIcore & $08: 30$ & Value / & ONS \\
\hline Retail Sales Less Auto & RSLA & $08: 30$ & Rate / \% Change & ONS \\
\hline Claimant Count Rate SA & $\mathrm{CCR}$ & $08: 30$ & Rate /\% RATIO & ONS \\
\hline ILO Unemployment Rates & ILOUP & $08: 30$ & Rate /\% RATIO & ONS \\
\hline \multicolumn{5}{|c|}{ Inflation Indicators } \\
\hline Consumer Price Index EU Harmonized & PPI & $08: 30$ & Rate / \% Change & ONS \\
\hline CPI Ex Food and Energy & CPIC & 08:30 & Rate / \% Change & ONS \\
\hline \multicolumn{5}{|c|}{ Monetary Policy Indicators } \\
\hline PSNCR Net Borrowing & PSNCR & $08: 30$ & Value / Billions & ONS \\
\hline PSNCR Public Sector Net Cash Requirement & PSNCRPS & $08: 30$ & Value / Billions & ONS \\
\hline Bank of England Official Bank Rate & BoER & $11: 00$ & Value / Billions & BoE \\
\hline \multicolumn{5}{|c|}{ Foreign Trade Indicators } \\
\hline Visible Trade Balance & $\mathrm{TB}$ & $08: 30$ & Value / Millions & ONS \\
\hline
\end{tabular}

Table (b): United Kingdom (U.K.) 


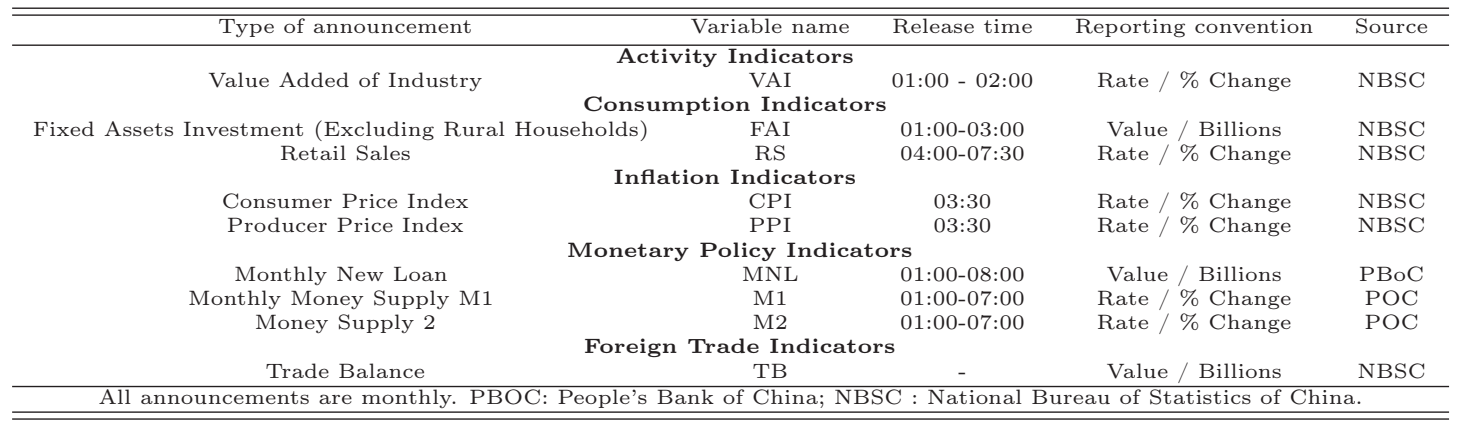

Table (c): China $(\mathrm{CN})$

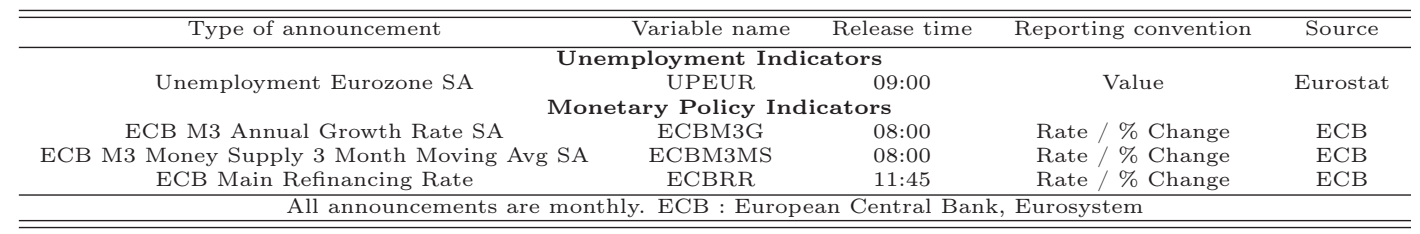

Table (d): Euro Zone (EC)

\begin{tabular}{|c|c|c|c|c|}
\hline Type of announcement & Variable name & Release time & "Reporting convention & Source \\
\hline \multicolumn{5}{|c|}{ Activity Indicators } \\
\hline Industrial Production & IP & $23: 50-00: 50$ & Rate/\% Change & MET\&I \\
\hline Tertiary Industry & TI & $23: 50-00: 50$ & Rate/\% Change & MET\&I \\
\hline Machine Orders & MO & $23: 50-00: 50$ & Rate/\% Change & ESRIJ \\
\hline Economy Watchers Survey Current Conditions & EWSC & $22: 50-23: 50$ & Value / & JMA \\
\hline \multicolumn{5}{|c|}{ Consumption and Employment Indicators } \\
\hline Loans and Discounts Outstanding Total and Shinkin Banks & LDOSB & $22: 50$ & Value / & BoJ \\
\hline Japan Housing Starts & $\begin{array}{l}\text { ty Indicators } \\
\text { JAS }\end{array}$ & 04:00/ 05:00 & Rate / \% Change & MLIT \\
\hline \multicolumn{5}{|c|}{ Monetary Policy Indicators } \\
\hline Japan Money Stock M2 avg amt outstanding & M2 & - & Rate/\% Change & BoJ \\
\hline \multirow{2}{*}{\multicolumn{5}{|c|}{ Foreign Trade Indicators }} \\
\hline & & & & \\
\hline \multirow{3}{*}{$\begin{array}{c}\text { Japan Balance of Payments Current Account } \\
\text { Japan Merchandise Trade Balance } \\
\text { Trade Balance }\end{array}$} & BPAB & $22: 50 / 23: 50$ & Value / Billions JPY & MIAC \\
\hline & MTB & $22: 50 / 23: 50$ & Value / Billions JPY & MIAC \\
\hline & $\mathrm{TB}$ & $22: 50 / 23: 50$ & Value / Billions JPY & MIAC \\
\hline $\begin{array}{l}\text { All announcements are monthly. MET\&IJ: Ministry of E } \\
\text { Institute Japan; MFJ: Ministry of Finance Jap } \\
\text { MLIT Ministry of Land, Infrastructure, Transport }\end{array}$ & $\begin{array}{l}\text { Trade \& Ind } \\
\text { LAC: Ministry }\end{array}$ & $\begin{array}{l}\text { ry Japan; ES } \\
\text { Internal Affai } \\
\mathrm{k} \text { of Japan; J }\end{array}$ & $\begin{array}{l}\text { Economic and Social } \\
\text { and Communications; }\end{array}$ & \\
\hline
\end{tabular}

Table (e): Japan (JP) 


\section{APPENDIX 4 : Unscheduled event news}

\begin{tabular}{|c|c|c|}
\hline Date & Category & Unexpected Events \\
\hline $01 / 06 / 2007$ & $\mathrm{RA}^{*}$ & SP500 and Moody's Downgrade over 100 bonds backed by second-lien subprime mortgages. \\
\hline $20 / 07 / 2007$ & Politic & FED - Bernanke warned that the crisis in the subprime lending market could cost up to $100 \mathrm{~B} \$$. \\
\hline $06 / 08 / 2007$ & Default & American Home Mortgage - Files for chapter 11 bankruptcy protection. \\
\hline $09 / 08 / 2007$ & Market & First incidence of major liquidity squeeze in global money markets. \\
\hline $12 / 12 / 2007$ & Politic & FOMC Board - Announces the creation of a term auction facility (TAF). \\
\hline $12 / 12 / 2007$ & Politic & FOMC - Approved SWAP agreements which will provide $20 \mathrm{~B} \$$ to the ECB and $4 \mathrm{~B} \$$ to the Swiss NB. \\
\hline $04 / 01 / 2008$ & Saving & W.Bush meets with the Working Group on Financial Markets (WGFM) chaired by H.Paulson. \\
\hline $22 / 01 / 2008$ & Politic & FED-new panic in the global credit market leads the fed to cut interest rate by 75 basis points. \\
\hline $30 / 01 / 2008$ & Politic & ECB - The leaders of europe's biggest economies meet in London for a credit crunch summit with warning to rating ag. \\
\hline $13 / 02 / 2008$ & Politic & FED - Signs the economic stimulus act 2008 (public law 110-185) into law. \\
\hline $15 / 02 / 2008$ & RA & Moody's Pulled its AAA rating from Financial Guarantee Insurance Company. \\
\hline $17 / 02 / 2008$ & Politic & Britain announces the nationalization of Northern Rock. \\
\hline $14 / 03 / 2008$ & FUSAC & Bear Stearns near collapse - Fed arranges financing with JP Morgan Chase. \\
\hline $17 / 03 / 2008$ & FUSAC & B.Stearns is acquired by JP Morgan for $240 \mathrm{M} \$$ a fraction of its share price, in deal backed by $30 \mathrm{~B} \$$ in FED loans. \\
\hline $22 / 04 / 2008$ & Saving & BoE offers to acquire UK bank's mortgage-backed securities for up to three years in return for Treasury Bills. \\
\hline $09 / 05 / 2008$ & RA & Two major rating agencies downgrade the AIG Co. to AA- after hearing the news of the losses but left the insurance Co. subsidiaries at AA + . \\
\hline $13 / 07 / 2008$ & Saving & U.S. Treasury Department announces increase of credit lines of Fannie Mae and Freddie Mac. \\
\hline $15 / 09 / 2008$ & Default & Lehman Brothers declares bankruptcy, the largest ever in the United States. \\
\hline $29 / 09 / 2008$ & Saving & U.S. House Rejects $700 \mathrm{~B} \$$ Financial-Rescue Plan. \\
\hline $13 / 10 / 2008$ & Saving & Dutch-Credit - Germany approves a plan to inject $500 \mathrm{~B} €$ into credit markets. \\
\hline $17 / 10 / 2008$ & Politic & The European Union 27 leaders sign off on a joint $2.7 \mathrm{~T} \$$ bank bailout plan after a 2 -day summit in Brussels. \\
\hline $20 / 10 / 2008$ & Saving & The French government announces it will inject $10.5 \mathrm{~B} €$ into France's six largest banks. \\
\hline $27 / 10 / 2008$ & Default & Iceland's Kaupthing Bank Defaults on Its Samurai Bonds as Yields Hit $450 \%$. \\
\hline $09 / 11 / 2008$ & Saving & AIG receives a revised $150 \mathrm{~B} \$$ government bailout plan that will reduce interest payments and give it more time to sell assets. \\
\hline $14 / 11 / 2008$ & Credit losses & Freddie Mac Posts Record Loss, Asks Treasury for $13.8 \mathrm{~B} \$$. \\
\hline $09 / 12 / 2008$ & RA & Goldman, UBS, Deutsch Bank Among 12 Banks Lowered by S\&P. \\
\hline $11 / 12 / 2008$ & Fraud US & Bernard Madoff was arrested and charged with securities fraud. \\
\hline $20 / 12 / 2008$ & RA & Sp500 downgrades the credit rating of eleven of the world's largest banks and says the global crisis could last longer than expected. \\
\hline $14 / 01 / 2009$ & RA & Sp500 cuts Greece's credit rating on debt. \\
\hline $15 / 01 / 2009$ & Saving & The US government has extended a $138 \mathrm{~B} \$$ bailout to Bank of America (BofA). \\
\hline $19 / 01 / 2009$ & RA & Sp500 slashes Spain's triple A rating (the highest rating available) on debt. \\
\hline $20 / 01 / 2009$ & Politic & First election of Barack Obama. \\
\hline $27 / 01 / 2009$ & Saving & Japan announces a $16.7 \mathrm{~B} \$$ stimulus package to help businesses that have been decimated by the global financial crisis. \\
\hline $12 / 03 / 2009$ & Saving & Japan will inject $\$ 1.2$ billion into regional banks Sapporo Hokuyo, Minami-Nippon, and Fukuho bank, \\
\hline 08/04/2009 & Saving & US Tresory Gives insurance companies access to the $700 \mathrm{~B} \$ \mathrm{TARP}$ funds. \\
\hline $05 / 04 / 2010$ & Media & WikiLeaks an online publisher of anonymous, covert, and classified material, leaks to the public, \\
\hline $20 / 04 / 2010$ & Disasters & BP Oil Spill Up to 260 million gallons of crude oil spewed into the Gulf of Mexico. \\
\hline $19 / 06 / 2010$ & Economy & Bank of China - Announced to further reform the RMB exchange rate regime and to enhance the RMB exchange rate flexibility. \\
\hline $11 / 03 / 2011$ & Disasters & A massive earthquake and tsunami devastates northeastern Japan, leaving 20,000 people dead or missing and unleashing a nuclear crisis. \\
\hline $29 / 04 / 2011$ & Wedding & Britain's Prince William and his bride Kate Middleton marry with huge crowds and a global TV audience. \\
\hline $02 / 05 / 2011$ & War & Al Qaeda chief Osama bin Laden believed responsible for the September 11, 2001 attacks on the U.S. is shot dead by US commandos in Pakistan. \\
\hline $05 / 08 / 2011$ & RA & The United States loses its perfect credit rating as Standard \& Poor's credit rating agency reduced the U.S. rating from AAA to AA \\
\hline $06 / 09 / 2011$ & Politic & Swiss National bank sets minimum exchange rate at CHF 1,20 per $€$. \\
\hline $27 / 10 / 2011$ & Politic & European Union leaders reach a ground-breaking deal to save the bloc's single currency, including a new rescue of Greece. \\
\hline $04 / 03 / 2012$ & Politic & Putin was elected to a third term as Russia's president. \\
\hline $12 / 05 / 2012$ & Market & The Facebook IPO Fiasco. \\
\hline
\end{tabular}


APPENDIX 5 : Matching between macroeconomic news and forex jumps

\begin{tabular}{|c|c|c|c|c|c|c|c|c|c|}
\hline COUNT. & News FX & Lib & EUR & GBP & JPY/USD & AUD & CAD & CHF & $\begin{array}{l}\text { \#Jump } \mid \text { News } \\
\text { \# }\end{array}$ \\
\hline \multirow{6}{*}{$\mathrm{CN}$} & CNFAI & Fixet Asset Invest & NM & NM & NM & NM & NM & 1 & 1 \\
\hline & CNMNL & Monthly New Loan & NM & NM & NM & NM & NM & 1 & 1 \\
\hline & CNMS1 & Money Supply M1 & $\mathrm{NM}$ & $\mathrm{NM}$ & NM & NM & NM & 1 & 1 \\
\hline & CNMS2 & Money Supply M2 & NM & 1 & NM & NM & $\mathrm{NM}$ & 1 & 2 \\
\hline & CNRS & Retail Sales & NM & $\mathrm{NM}$ & NM & NM & $\mathrm{NM}$ & 1 & 1 \\
\hline & CNVAI & Value Added of Ind. & NM & $\mathrm{NM}$ & NM & NM & $\mathrm{NM}$ & 1 & 1 \\
\hline \multirow{4}{*}{ UE } & ECBM3G & M3 Annual Growth & NM & 1 & NM & NM & NM & NM & 1 \\
\hline & ECBM3MS & Money Supplu M3 & NM & 1 & NM & NM & NM & NM & 1 \\
\hline & ECBRR & Refinancing Rate & 3 & NM & NM & NM & $\mathrm{NM}$ & 2 & 2 \\
\hline & ECBUNEMP & Unemp. Rate UE & NM & 2 & NM & NM & $\mathrm{NM}$ & $\mathrm{NM}$ & 1 \\
\hline \multirow{11}{*}{ JP } & JPBPCA & Balance of Payments CA & 1 & $\mathrm{NM}$ & $\mathrm{NM}$ & 1 & NM & NM & 2 \\
\hline & JPEWSC & Economy Watchers Surv. & NM & $\mathrm{NM}$ & NM & 1 & $\mathrm{NM}$ & $\mathrm{NM}$ & 1 \\
\hline & JPHS & Housing Starts & NM & 1 & NM & 2 & NM & NM & 2 \\
\hline & JPIP & Industrial Prodction & 1 & 1 & NM & 1 & 1 & NM & 4 \\
\hline & JPLDAAO & Loans \& Discounts & 1 & $\mathrm{NM}$ & NM & NM & $\mathrm{NM}$ & $\mathrm{NM}$ & 1 \\
\hline & JPMO & Machine Orders & 1 & NM & NM & 1 & NM & NM & 2 \\
\hline & JPMS2 & Money Stock M2 & 2 & $\mathrm{NM}$ & NM & NM & $\mathrm{NM}$ & $\mathrm{NM}$ & 1 \\
\hline & JPMS3 & Money Stock M3 & 2 & $\mathrm{NM}$ & NM & NM & $\mathrm{NM}$ & $\mathrm{NM}$ & 1 \\
\hline & JPMTB & Merchandise Trade Bal. & NM & NM & NM & 1 & NM & NM & 1 \\
\hline & JPTI & Tertiary Industry & NM & NM & 1 & NM & NM & NM & 1 \\
\hline & JPTSB & Trade Balance & NM & NM & NM & 1 & NM & NM & 1 \\
\hline \multirow{15}{*}{ U.K. } & UKBoER & BoE Official rate & 2 & NM & NM & NM & 1 & 1 & 3 \\
\hline & UKBoEAP & BoE Asset Purchase Prog & 1 & $\mathrm{NM}$ & NM & NM & 1 & 1 & 3 \\
\hline & UKCCR & Claimant Count Rate & $\mathrm{NM}$ & 1 & NM & NM & NM & NM & 1 \\
\hline & UKCPIC & CPI Ex Food \& Energy & NM & $\mathrm{NM}$ & NM & 1 & $\mathrm{NM}$ & $\mathrm{NM}$ & 1 \\
\hline & UKCPIEUHM & CPI EU Harmonized & NM & NM & NM & 1 & $\mathrm{NM}$ & $\mathrm{NM}$ & 1 \\
\hline & UKGDPQOQ & GDP & 2 & 1 & 2 & NM & $\mathrm{NM}$ & $\mathrm{NM}$ & 3 \\
\hline & UKHBOS & House Price $3 \mathrm{Mth}$ & NM & 1 & NM & NM & NM & NM & 1 \\
\hline & UKPSNCR & PSNCR Net Borrowing & 1 & NM & NM & NM & NM & 2 & 2 \\
\hline & UKPSNCRPS & PSNCR Public Sector & 1 & NM & NM & NM & NM & 2 & 2 \\
\hline & UKRICSWHM & RICS UK \& Wales Housing & NM & NM & NM & 1 & NM & NM & 1 \\
\hline & UKRPIAI & RPI All Items & NM & $\mathrm{NM}$ & NM & 1 & $\mathrm{NM}$ & $\mathrm{NM}$ & 1 \\
\hline & UKRPILMI & RPI less Mortgage Interest & NM & NM & NM & 1 & $\mathrm{NM}$ & $\mathrm{NM}$ & 1 \\
\hline & UKRSLA & Retail Sales Less Auto & 1 & NM & NM & 1 & NM & 1 & 3 \\
\hline & UKTB & Trade Balance & NM & $\mathrm{NM}$ & NM & NM & $\mathrm{NM}$ & 1 & 1 \\
\hline & UKUPILO & ILO Unemp. Rate & NM & 1 & NM & NM & NM & NM & 1 \\
\hline \multirow{42}{*}{ U.S. } & USARSLA & Retail Sales Less Auto & NM & $\mathrm{NM}$ & 2 & 1 & 1 & 1 & 4 \\
\hline & USCB & Census Bureau & NM & 1 & NM & 1 & NM & NM & 2 \\
\hline & USCBLI & Conference Board Leading & 1 & 1 & 2 & NM & NM & 3 & 4 \\
\hline & USCJC & Continuing Jobless & 4 & NM & 3 & 1 & 7 & 6 & 5 \\
\hline & USCPIC & CPI Ex Food \& Energy & NM & $\mathrm{NM}$ & NM & 1 & NM & NM & 1 \\
\hline & USCPIM & Consumer Price Index & NM & $\mathrm{NM}$ & NM & 1 & $\mathrm{NM}$ & $\mathrm{NM}$ & 1 \\
\hline & USCU & Capacity Utilization & 1 & 2 & NM & NM & 2 & 2 & 4 \\
\hline & USDGNOIM & Durable Good Orders In. & NM & 1 & NM & 1 & 2 & 1 & 4 \\
\hline & USDGNOTM & DGO ex Transport & NM & 1 & NM & 1 & 2 & 1 & 4 \\
\hline & USECCW & Cost Civilian Workers & NM & 1 & 1 & NM & NM & 1 & 3 \\
\hline & USEHS & Existing Home Sales & NM & 1 & 1 & 1 & 1 & NM & 4 \\
\hline & USENFPMI & NFP Manufacturing Ind. & 1 & $\mathrm{NM}$ & 6 & NM & 2 & 1 & 4 \\
\hline & USENFP & NonFarm Payrolls & 1 & NM & 6 & NM & 2 & 1 & 4 \\
\hline & USESMS & Empire State manuf. Surv. & 1 & 1 & NM & 1 & 1 & NM & 4 \\
\hline & USFFTR & Federal Funds Rate & 3 & 2 & 3 & 4 & 3 & 3 & 6 \\
\hline & USFNT & Foreign Net Trans. & 1 & 2 & NM & NM & 1 & 1 & 4 \\
\hline & USFRCCD & FED Consumer Credit & $\mathrm{NM}$ & $\mathrm{NM}$ & 1 & 1 & 1 & $\mathrm{NM}$ & 3 \\
\hline & USIPI & Import Price Idx & NM & NM & NM & 1 & 2 & NM & 2 \\
\hline & USIOE & Economic Optimism & NM & 1 & NM & 2 & 1 & $\mathrm{NM}$ & 3 \\
\hline & USIP & Industrial Prodction & 1 & 2 & NM & NM & 2 & 2 & 4 \\
\hline & USISM & ISM Manufacturing & NM & $\mathrm{NM}$ & 2 & NM & $\mathrm{NM}$ & $\mathrm{NM}$ & 1 \\
\hline & USMNCR & MNI Chicago Report & NM & 1 & 1 & NM & 1 & NM & 3 \\
\hline & USMTI & Manuf.\& Trade Inv. & NM & NM & 2 & NM & NM & 1 & 2 \\
\hline & USMWI & Merchandise Wholesalers Inv. & NM & 1 & NM & 1 & NM & NM & 2 \\
\hline & USNAHBMI & NAHBM Index & 1 & 1 & 1 & 2 & NM & NM & 4 \\
\hline & USNOFHSAM & New One Family Houses & 1 & 1 & NM & NM & NM & 1 & 3 \\
\hline & USNPOHUSS & NewPrivately Owned Housing & NM & NM & 1 & 1 & 1 & 1 & 4 \\
\hline & USPCE & Personal Consumption Expend. & NM & $\mathrm{NM}$ & 2 & NM & NM & NM & 1 \\
\hline & USPPHIL & Philadelphia Fed Survey & 1 & 1 & 3 & NM & $\mathrm{NM}$ & 3 & 4 \\
\hline & USPHA & Private Housing & NM & NM & 1 & 1 & 1 & 1 & 4 \\
\hline & USPHS & Pending Home Sales & NM & 2 & NM & NM & NM & NM & 1 \\
\hline & USPHUSS & Private Housing Started & NM & NM & NM & NM & 1 & $\mathrm{NM}$ & 1 \\
\hline & USPPIC & Producer Price Index & NM & $\mathrm{NM}$ & 1 & 1 & 1 & NM & 3 \\
\hline & USPPIC & PPI ex Food $\backslash \&$ Energy & NM & $\mathrm{NM}$ & 1 & 1 & 1 & NM & 3 \\
\hline & USPPIG & PPI Total Goods & NM & $\mathrm{NM}$ & 1 & 1 & 1 & NM & 3 \\
\hline & USPTHAB & Private Total Housing & $\mathrm{NM}$ & $\mathrm{NM}$ & NM & NM & 1 & $\mathrm{NM}$ & 1 \\
\hline & USTB & Trade Balance & $\mathrm{NM}$ & $\mathrm{NM}$ & 1 & 1 & 2 & 2 & 4 \\
\hline & USTFBDSD & Treas.Fed Budget Debt & 1 & 1 & 1 & 1 & 1 & NM & 5 \\
\hline & USIJC & Initial Jobless Claims & 4 & NM & 3 & 1 & 7 & 6 & 5 \\
\hline & USUMSCFS & U.Michigan Consumer Sentim. & NM & NM & 1 & NM & 1 & 1 & 3 \\
\hline & USUP & Unemp. Rate & 1 & NM & 6 & NM & 2 & 1 & 4 \\
\hline & ALL Matching & & 42 & 35 & 56 & 42 & 54 & 56 & 285 \\
\hline
\end{tabular}




\section{References}

Andersen, Bollerslev, D. and Vega (2007). Real-time price discovery in global stock, bond and foreign exchange markets. Journal of International Economics, 73(2):251 - 277.

Andersen, T. G. and Bollerslev, T. (1997). Intraday periodicity and volatility persistence in financial markets. Journal of Empirical Finance, Elsevier, 4(2-3).

Andersen, T. G. and Bollerslev, T. (1998). Deutsche mark-dollar volatility: Intraday activity patterns, macroeconomic announcements, and longer run dependencies. Journal of Finance, 53(1):219-265.

Andersen, T. G., Bollerslev, T., Diebold, F. X., and Vega, C. (2003). Micro effects of macro announcements: Real-time price discovery in foreign exchange. American Economic Review, 93(1):38-62.

Balduzzi, P., Elton, E. J., and Green, T. C. (2001). Economic news and bond prices: Evidence from the u.s. treasury market. The Journal of Financial and Quantitative Analysis, 36(4):pp. 523-543.

Ball, R. and Brown, P. (1968). An empirical evaluation of accounting income numbers. Journal of Accounting Research, Vol. 6, No. 2:pp. 159-178.

Barndorff-Nielsen, O. and Shephard (2006). Econometrics of testing for jumps in financial economics using bipower variation. Journal of Financial Econometrics, 4(1):1-30.

Barndorff-Nielsen, O. E. and Shephard, N. (2004). Power and bipower variation with stochastic volatility and jumps. Journal of Financial Econometrics, 2(1):1-37.

Black, F. (1976). Studies in stock price volatility changes. Proceedings of the 1976 Meetings of the American Statistical Association, Business and Economics Statistics Section, 17\%181.

Boudt, K., Croux, C., and Laurent, S. (2011). Robust estimation of intraweek periodicity in volatility and jump detection. Journal of Empirical Finance, 18(2):353-367.

Calzolari, G. and Fiorentini, G. (1998). A tobit model with garch errors. Econometric Reviews, 17(1):85-104.

Cheung, Y.-W. and Chinn, M. D. (2001). Currency traders and exchange rate dynamics: a survey of the us market. Journal of International Money and Finance, 20(4):439-471.

Erdemlioglu, D., Laurent, S., and Neely, C. J. (2012). Econometric modeling of exchange rate volatility and jumps. Working Papers 2012-008, Federal Reserve Bank of St. Louis.

Evans, M. D. and Lyons, R. K. (2005). Do currency markets absorb news quickly? Journal of International Money and Finance, 24(2):197 - 217. Exchange Rate Economics. 
Fama, E. F. (1965). The behavior of stock-market prices. The Journal of Business, 38(1):pp. 34-105.

Fama, E. F. and Schwert, G. W. (1977). Asset returns and inflation. Journal of Financial Economics, 5(2):115-146.

Fan, Y. and Fan, J. (2011). Testing and detecting jumps based on a discretely observed process. Journal of Econometrics, 164(2):331-344.

Galambos, J. (1987). The Asymptotic Theory of Extreme Order Statistics. Robert E. Krieger.

Glosten, L. R., Jagannathan, R., and Runkle, D. E. (1993). On the relation between the expected value and the volatility of the nominal excess return on stocks. Staff Report 157, Federal Reserve Bank of Minneapolis.

Jiang, G. J. and Oomen, R. C. (2008). Testing for jumps when asset prices are observed with noise-a \&quot;swap variance\&quot; approach. Journal of Econometrics, 144(2):352-370.

Laakkonen, H. (2007). The impact of macroeconomic news on exchange rate volatility. Finnish Economic Papers, 20(1):23-40.

Lahaye, J., Laurent, S., and Neely, C. J. (2011). Jumps, cojumps and macro announcements. Journal of Applied Econometrics, 26(6):893-921.

Lee, S. and Mykland, P. (2012). Jumps in equilibrium prices and market microstructure noise. Journal of Econometrics, 168(2):396-406.

Lee, S. S. and Mykland, P. A. (2008). Jumps in financial markets: A new nonparametric test and jump dynamics. Review of Financial Studies, 21(6):2535-2563.

Lunde, A. and Hansen, P. R. (2004). Realized variance and iid market microstructure noise. Econometric Society 2004 North American Summer Meetings 526, Econometric Society.

Maddala, G. S. (1983). Limited-Dependent and Qualitative Variables in Econometrics. Cambridge University Press. Cambridge Books Online.

Mandelbrot, B. (1963). The variation of certain speculative prices. The Journal of Business, $36: 394$. 